\title{
Off-Design and Annual Performance Analysis of Supercritical Carbon Dioxide Cycle with Thermal Storage for CSP application
}

\author{
Dhinesh Thanganadar $^{\mathrm{a}}$, Francesco Fornarelli ${ }^{\mathrm{b}, \mathrm{c}}$, Sergio Camporeale $^{\mathrm{b}}$, Faisal Asfand ${ }^{\mathrm{a}, \mathrm{d}}$, \\ Kumar Patchigolla ${ }^{\mathrm{a}, *}$
}

\begin{abstract}
${ }^{a}$ School of Water, Energy and Environment (SWEE), Cranfield University, Cranfield, MK43 OAL, UK
${ }^{b}$ Dipartimento di Meccanica, Matematica e Management (DMMM) Politecnico di Bari, Bari, Italy

${ }^{c}$ National Group of Mathematical Physics (GNFM), National Institute of High Mathematics (INDAM)

${ }^{d}$ The School of Computing and Engineering, University of Huddersfield, Huddersfield, HD1 3DH, UK

*Corresponding author-E-mail addresses: k.patchigolla@cranfield.ac.uk
\end{abstract}

\begin{abstract}
Supercritical Carbon Dioxide $\left(\mathrm{sCO}_{2}\right)$ cycles can achieve higher efficiency compared to steam-Rankine or AirBrayton cycles, therefore they are promising for concentrated solar power applications. In the present work a recompression $\mathrm{sCO}_{2}$ cycle is connected to a central-tower solar field with two-tank thermal storage delivering molten chloride salt at $670^{\circ} \mathrm{C}$. Although $\mathrm{sCO}_{2}$ cycles show higher design efficiency, the off-design efficiency is highly sensitive to the ambient conditions, impacting the power block net-power and heat input. The temperature of the molten-salt exiting from the power block and returning to the cold storage tank increases by $46^{\circ} \mathrm{C}$ with respect to the design value when the compressor inlet temperature is raised by $13^{\circ} \mathrm{C}$ relative to the design condition of $42^{\circ} \mathrm{C}$, which implies that the capacity of the thermal storage reduces by $25 \%$. The main focus of this work is to investigate the off-design performance of a $\mathrm{sCO}_{2}$ recompression cycle under variable ambient temperature, molten-salt inlet temperature and molten-salt flow rate. Multi-objective optimisation is carried-out in off-design conditions using an in-house code to explore the optimal operational strategies and the Pareto fronts were compared. Since the power cycle can either be operated in maximum power mode or maximum efficiency mode, this study compares these two operational strategies based on their annual performance. Results indicate that the capacity factor of the concentrated solar power can be increased by $10.8 \%$ when operating in maximum power mode whilst the number of start-ups is reduced by about $50 \%$ when operating in maximum efficiency mode.
\end{abstract}

Keywords: Supercritical $\mathrm{CO}_{2}$ cycle, CSP, Annual Performance, Multi-Objective Optimisation, Thermal Energy Storage, Off-design
Nomenclature
CIT Compressor Inlet Temperature
CSP Concentrated Solar Power
HT High Temperature
HTR High Temperature Recuperator 


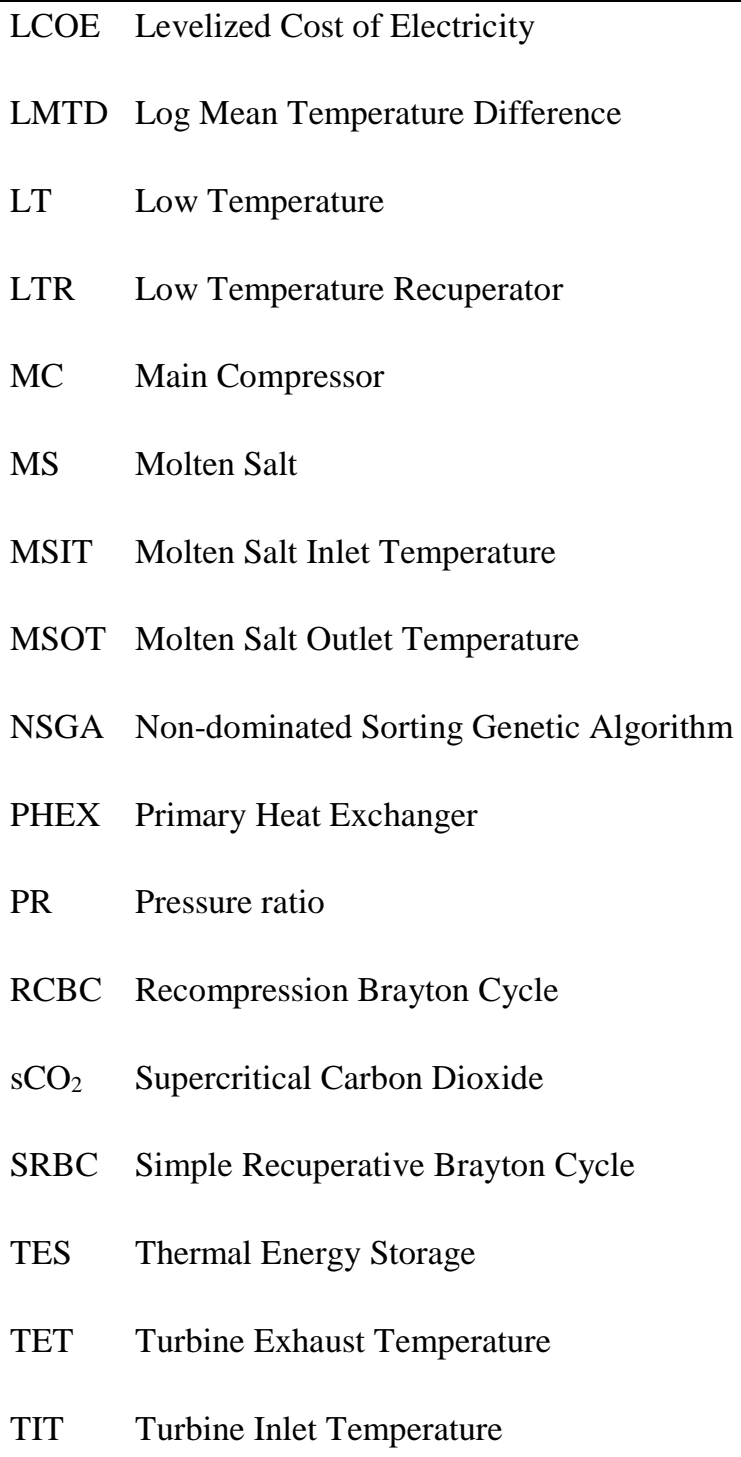

\section{Introduction}

The Supercritical Carbon Dioxide $\left(\mathrm{sCO}_{2}\right)$ Brayton cycle has many advantages over the conventional steam Rankine/ Joule-Brayton cycles owing to its compact footprint and higher efficiency when the turbine inlet temperature is $>550{ }^{\circ} \mathrm{C}$ [1]. $\mathrm{sCO}_{2}$ also has high thermal stability at an elevated temperature, is nonflammable and nontoxic compared to ORC plants. Because of these benefits, $\mathrm{sCO}_{2}$ cycles are being considered for a range of applications including nuclear [1], concentrating solar power (CSP) [2], fossil fuel-fired plants, and waste heat recovery [3]. Many researchers have extensively studied the performance of $\mathrm{sCO}_{2}$ cycles [4] and numerous different cycles have been proposed [5]. In particular, Crespi et al. [4] reviewed and categorised forty-two of them while Thanganadar et al. [3] studied five $\mathrm{sCO}_{2}$ cycle configurations for sensible heat source applications, proposing a set of performance maps to estimate the performance of $\mathrm{sCO}_{2}$ cycles for the bottoming cycle. Marchionni et al. [5] performed first and second-law analysis for eight Joule-Brayton $\mathrm{SCO}_{2}$ cycles integrated with 
a high-grade waste heat sources, concluding that the unit cost $(\$ / \mathrm{kWe})$ of a cycle follows a parabolic shape, which has an optimum for different exhaust gas temperature, primarily dictated by the cost of the high-temperature heat exchangers. Giovannelli et al. [6] discussed the design processes of radial turbomachinery for a medium-scale $\mathrm{sCO}_{2}$ power block using one-dimensional and three-dimensional numerical simulation. Demonstration facilities and pilot plants have been built in recent years for testing the performance and reliability of $\mathrm{sCO}_{2}$ plants. National Renewable Energy Laboratory (NREL), USA tested a $520 \mathrm{~kW}_{\text {th }}$ pilot plant [7] and is building a scale-up facility of $10 \mathrm{MW}_{\mathrm{e}}$ [8], which is designed to operate at $715.9{ }^{\circ} \mathrm{C}$ turbine inlet temperature [8,9]. As far as commercial applications are concerned, Echogen ${ }^{\circledR}$ has commercialised a packaged unit for Waste Heat Recovery (WHR) applications [10].

The critical point of carbon dioxide is $30.98{ }^{\circ} \mathrm{C}, 73.8$ bar while the cycle maximum pressure is typically limited to around 300 bar due to material and economic limitations. This makes the cycle pressure ratio less than 4 , which limits the specific work and temperature drop across the turbine, making recuperation necessary in order to increase cycle efficiency. Several recuperated $\mathrm{sCO}_{2}$ cycles have been proposed in the literature [4]. The basic configuration is the closed-loop simple recuperative Brayton cycle (SRBC), however the degree of recuperation is limited by the occurrence of a pinch point in the recuperator. This can be avoided by the recompression Brayton cycle (RCBC) where the recuperator is split into two heat exchangers and the mass flow rate to the lowtemperature recuperator cold-side is lowered to maximise recuperation. Although advanced cycles, such as partial cooling cycles, precompression, cascade cycles are also proposed [4] to increase the cycle specific work, the $\mathrm{RCBC}$ is generally preferable due to its higher efficiency and simpler layout, which also makes it more suitable for CSP applications. Wang et al. [11] investigated the performance of a $\mathrm{RCBC}$ integrated with a transcritical $\mathrm{CO}_{2}$ $\left(\mathrm{tCO}_{2}\right)$ bottoming cycle to recover low-grade heat from the RCBC and compared six different fluids in closedloop cycle. Asfand et al. [12] integrated an absorption chiller with an SRBC cycle to chill the cooling water so that the efficiency penalty at higher ambient temperatures can be reduced. Linares et al. [13] proposed a modification to RCBC that facilitate heat addition at a lower pressure to enable the use of conventional shell and tube heat exchangers in order to reduce the cost of the PHEX for CSP applications. Clementoni et al. provided the steady-state [14], off-design [15] and transient [16] operational results of a $100 \mathrm{~kW}_{\mathrm{e}}$ experimental facility at the Naval Nuclear Laboratory, USA. Clementoni et al. [17] also reported the operational results of the test facility for different compressor inlet temperature (CIT).

Although the design point performance of RCBC is extensively studied, the off-design performance of an integrated $\mathrm{sCO}_{2}$ cycle with TES- CSP appears seldom investigated. This is concerning for a CSP plant, because 
they often encounter off-design operation due to the volatility of the renewable energy source. Dyreby et al. [7] have developed a FORTRAN based design and off-design code that can simulate the recompression cycle. They proposed an empirical turbomachinery scaling method derived from Sandia National Laboratory test loop compressor. The plant solving procedure is specific to recompression cycle which can be cumbersome and error prone when changing the cycle configuration. Tse et al. [8] integrated a primary heat exchanger (PHEX) code with Dyreby's code through an external iterative procedure, concluding that the off-design performance not only effects on the cycle performance, but also can influence the capacity of the TES and the solar receiver performance. Clementoni et al. [18] analysed the effect of compressor inlet pressure on the performance of the $\mathrm{sCO}_{2}$ cycle and compared with the operational results, concluding that the cycle power output and efficiency are directly affected by the compressor inlet density. Anselmi et al. [19] explained the test facility operations along with the preliminary modelling works of compressor design and control strategy. Duniam et al. [20] analysed the off-design performance of a $\mathrm{SCO}_{2}$ cycle integrated with a natural draft dry cooling tower, concluding that the cycle net power reduces by $10 \%$ for each $10{ }^{\circ} \mathrm{C}$ increase in ambient temperature above the design temperature when cycle inventory and turbine inlet temperature (TIT) are maintained at the design values. Wright et al. [21] investigated four different $\mathrm{sCO}_{2}$ cycle control strategies for a waste heat recovery application, including; cooling air fan speed control, boost compressor speed control, split fraction control and compressor inlet pressure control. They conclude that the combination of all four controls provide an efficient way to mitigate the effects of heat rejection at a higher ambient temperature. Wang et al. [22] analysed the performance of a direct air-cooled $\mathrm{sCO}_{2}$ cycle under off-design conditions, observing that the cooling-tower approach temperature varies nonlinearly with the ambient temperature. Son et al. [23] developed a deep neural-network based turbomachinery off-design model for which the training data were generated from a one-dimensional mean-line code for $\mathrm{sCO}_{2}$ application. Aforementioned studies investigated the performance RCBC for different control techniques, however, there has been no systematic study that explores the optimal operational space (multi-dimensional Pareto front) for different boundary conditions, and investigate the trends of critical control variables including minimum/ maximum pressure, shaft speed and split fraction that aids in developing the optimal control strategy.

Several research groups have performed transient simulations of the standard recompression cycle [10-14], finding that inventory control provides higher efficiency at part load compared to other control techniques such as turbine bypass, turbine inlet temperature and throttling control. Inventory control turndown is limited, however, by the size of the $\mathrm{CO}_{2}$ storage tank and the pressure pinch between that storage tank pressure and the system pressure. Although a bigger inventory storage tank can push the $\mathrm{sCO}_{2}$ cycle turndown ratio further, the optimal 
size is an economical trade-off between the CAPEX and improvement in annual energy generation [15]. Researchers have proposed [24] that turbine bypass control or throttle control is required to extend the plant turndown further and to have a faster response during load throw-off as inventory control is slower [25], which is supported by previous operational experience of closed-loop Brayton cycles [26].

Bennett et al. [16] observed that the off-design cycle pressure ratio of $\mathrm{sCO}_{2}$ cycle reduces at higher ambient temperatures. Consequently, the turbine expansion ratio reduces which increases, the turbine exhaust temperature (TET) for a given TIT and since $\mathrm{sCO}_{2}$ cycles are recuperative Brayton cycles, this higher TET increases the recuperation. Consequently the cold stream inlet temperature to the primary heat exchanger increases, which causes the molten salt outlet temperature (MSOT) to increase at higher ambient temperatures. This negatively affects solar field performance in two ways: 1) the energy absorption window of the solar receiver reduces when the molten salt mass flow reaches its maximum flow limit, and 2) the cold storage tank temperature gradually increases, reducing the capacity of thermal energy storage (TES) as the differential temperature reduces. Tse et al. [8] quantified this reduction in TES capacity concluding that it can be as high as $20 \%$ of the design capacity at hot ambient temperatures. To eliminate the knock-on impact on the TES system an additional MSOT constraint should be considered in CSP-TES-sCO 2 cycle optimisation/operation. However, constraining the power cycle optimisation to respect an MSOT limitation close to its design value may negatively affect power cycle efficiency, although this has not been investigated in the existing literature.

For a CSP plant, the objective is to maximise the annual performance in order to reduce the levelised cost of electricity (LCOE). Reducing the total number of power block start-up/shut-down per annum, however, extends plant life and reduces the start-up/maintenance costs. Generally, the design criterion of the solar field is based on a "solar multiple", the ratio between the thermal power output of the solar field at the design solar radiation/sun angle, and the design thermal input of the power unit. A solar multiple greater than one is preferred in order to increase the plant capacity factor therefore there is often excess solar energy, which can be stored. The thermal storage capacity of a two-tank TES is typically rated based on the number of hours that the storage system can supply the power block design heat requirement. Implementing TES offers operational flexibility by disconnecting the solar field and power block enabling the thermal energy supply to the power block to be controlled without notably affecting the heat absorbed in the solar field and as long as the storage system capacity can absorb/supply any imbalance, the power block can be controlled in different ways.

The performance of a $\mathrm{sCO}_{2}$ cycle drops at a higher ambient temperature when the compressor inlet condition shifts away from the critical point, thus, increasing the compressive power. Maximising the power block off- 
design net power and net efficiency are not the same for a recuperated closed-loop Brayton cycle as the off-design cycle mass flow rate/the cycle pressure ratio varies depending on the objective [20]. The annual energy yield can be higher by maximising the net power, however, maximising the efficiency could be more attractive as $\mathrm{sCO}_{2}$ cycle performance is more sensitive to boundary conditions (ambient temperature, and the Molten Salt Inlet Temperature-MSIT). Several global plant operational strategies can therefore be defined to maximise a performance criterion at the current boundary conditions. Case 1) supply the energy required by the power block to maximise power generation and store the remaining energy in TES. Case 2) supply energy to the power block to maximise the power cycle instantaneous efficiency and store the remaining energy in TES. Case 3) give priority to fully charge the TES whilst generating power from the remaining energy. Maximising power block net power utilises the assets to their maximum capacity, however, it also penalises cycle efficiency significantly at higher ambient temperatures. Operating the power block in maximum efficiency mode during hot ambient conditions, while sacrificing some of the available instantaneous net power, allows storage of the remaining thermal energy for production of more power at a later time when cooler ambient conditions enable a higher efficiency, which could be attractive. This approach can be more effective for moderate Direct Normal Irradiance (DNI) days as plant shutdown can be avoided, thereby eliminating the associated start-up energy loss. To the best of the author's knowledge, there are no prior studies investigating how different plant operational strategies influence the annual performance of a $\mathrm{SCO}_{2}$ cycle.

This paper investigates the off-design performance of a $30 \mathrm{MW}_{\mathrm{e}} \mathrm{RCBC}$ power block for different boundary conditions such as variation of the heat transfer fluid (HTF) hot inlet temperature, molten salt mass flow rate, and ambient temperature with and without limiting the MSOT close to the design point, for the first time. A multiobjective optimisation approach is applied to the in-house cycle design and off-design codes, which maximises both net power and net efficiency by optimising the compressor inlet pressure, outlet pressure, split fraction and the molten salt mass flow rate, in order to explore the optimal operational space (Pareto fronts) in off-design operation. Firstly, the trade-off between the power cycle efficiency penalty when the MSOT is constrained proximate to its design value and the knock-on negative effect on TES capacity at higher ambient temperatures are studied. Secondly, the trends of control variables across the Pareto front, including the minimum pressure, maximum pressure, split fraction and MSOT are discussed which guides developing the plant control strategy and the optimal off-design compressor inlet pressure estimation method is proposed to maximise the cycle efficiency. The compressor operating point variation across the Pareto fronts are visualised by mapping the Pareto fronts on the compressor map for different boundary conditions. Finally, the annual performance of two different power 
cycle operational strategies 1 ) operating the power cycle in maximum power mode 2) operating the power cycle in maximum efficiency mode are simulated for the first time. The trade-offs between annual energy yield and the number of start-ups are quantified to appreciate the potential of these operating modes.

\section{2. $\mathrm{SCO}_{2}$ Cycle Configuration}

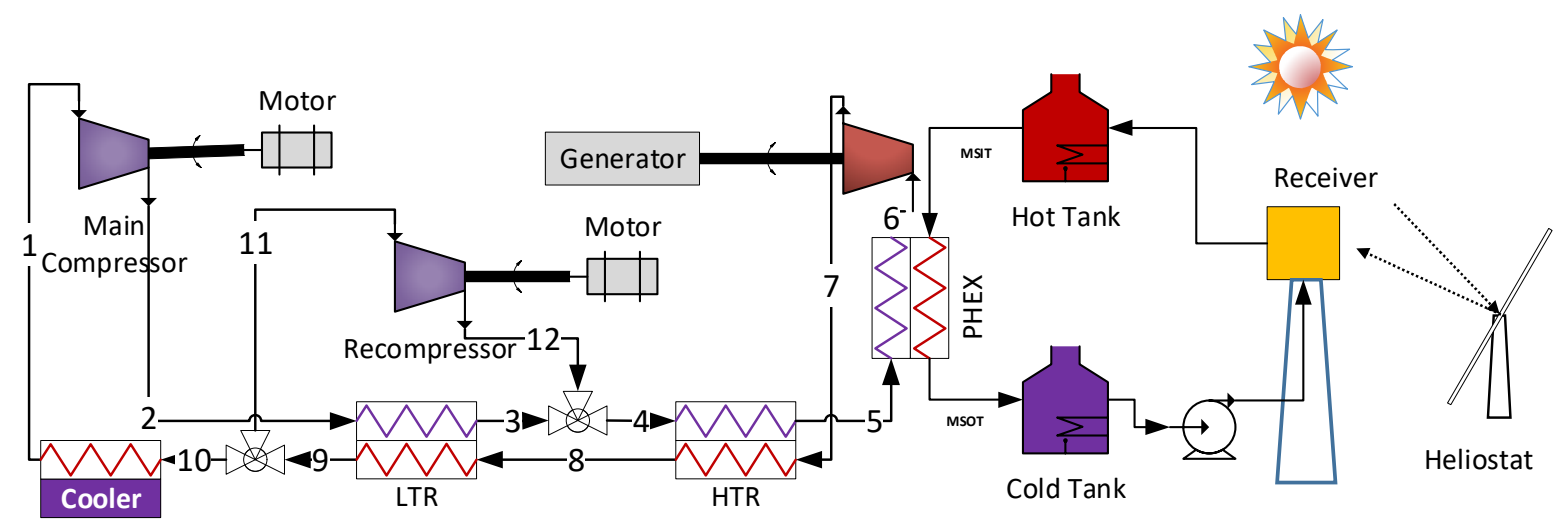

Fig. 1. Recompression cycle configuration

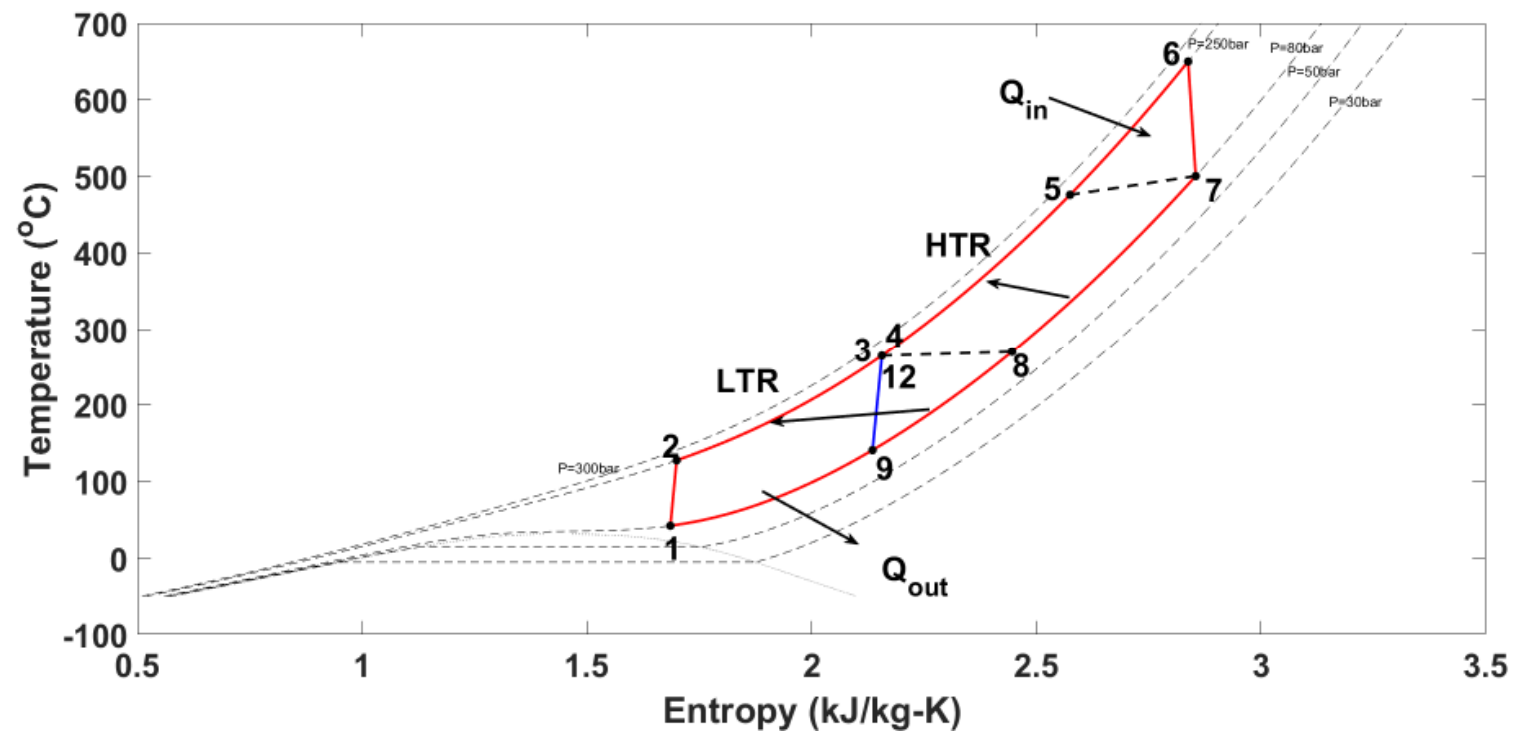

Fig. 2 Temperature-Entropy (T-S) diagram of recompression Brayton cycle (The dashed grey lines are the isobaric lines of $\mathrm{CO}_{2}$, the continuous grey line is the $\mathrm{CO}_{2}$ saturation curve)

A schematic of the RCBC is shown in Fig. 1 and the Temperature- Entropy (TS) diagram of the process is shown in Fig. 2. For the selected design parameters (Table 2), the states 12 and 4 overlay each other in the TS diagram. Processes 2 to 5 are recuperation, 5 to 6 heat addition and 9 to 1 heat rejection process. 
The precooler is air-cooled and the Primary Heat Exchanger (PHEX) is heated via the hot molten salt from the solar field. A central power tower-based solar field with a conventional two-tank sensible heat storage system is considered. Since the MSOT from the solar receiver is $670{ }^{\circ} \mathrm{C}$, conventional nitrate-based molten salts are not stable. The NREL $10 \mathrm{MW}_{\mathrm{e}}$ demonstration plant considered $\mathrm{MgCl}_{2}-\mathrm{KCl}$ (Mole: $32 \%-68 \%$ ) in order to achieve these higher operating temperatures $[8,9]$ and the same salt is therefore selected as both HTF and storage medium for this study.

For a closed-loop recuperative cycle, maximising efficiency tends to increase the cold stream inlet temperature to the PHEX so that the average heat addition temperature is increased, which improves the Carnot efficiency of the cycle provided that the recuperator circuit effectiveness is unaffected. On the other hand, increasing the cycle specific power tends to lower the cold stream inlet temperature to the PHEX so that heat addition to the cycle is maximised, with the trade-off to recuperation. The $\mathrm{sCO}_{2}$ mass flow rate, split fraction and the pressure ratio are all affected by the choice of objective function maximised i.e. efficiency or specific power. For a CSP plant, the product of solar field efficiency and power block efficiency has to be maximised. Integration of TES with optimal storage capacity allows storing of the energy absorbed from the solar field, which allows supplying the required amount of energy to the power block to maximise the objective function.

\section{Methodology for Thermodynamic Modelling}

The thermodynamic models for all the components, including; heat exchanger (one-dimensional), compressor/pump, turbine, valve, splitter, and mixer, were developed in MATLAB ${ }^{\circledR}$. The thermal physical properties of $\mathrm{sCO}_{2}$ are calculated using the REFPROP library (V9.1) [27], an iterative routine that minimises Helmholtz free energy. The thermal physical properties of the eutectic molten salt mixture $\mathrm{MgCl}_{2}-\mathrm{KCl}(\mathrm{Mole}$ : $32 \%-68 \%$ ) are calculated based on the work of $\mathrm{Xu}$ et al. [28] and listed in Table 1. The melting temperature of the salt is $424.4^{\circ} \mathrm{C}$, therefore, the cold storage tank temperature has to be above this value by a sufficient safety margin $\left(\sim 50^{\circ} \mathrm{C}[29]\right)$ to avoid salt freezing.

Table 1 Thermal-physical properties of molten salt

\begin{tabular}{|c|c|c|}
\hline Property & Unit & Function $\left(\mathbf{T}\right.$ in $\left.{ }^{\circ} \mathbf{C}\right)$ \\
\hline Isobaric Specific Heat $\left(C_{\mathrm{p}}\right)$ & $\mathrm{kJ} / \mathrm{kg}-\mathrm{K}$ & $0.9896+1.046 \times 10^{-4} \times(\mathrm{T}-430)$ \\
\hline Density $(\rho)$ & $\mathrm{kg} / \mathrm{m}^{3}$ & $1903.7-0.552 \times \mathrm{T}$ \\
\hline Dynamic Viscosity $(\mu)$ & $\mathrm{cP}$ & $14.965-0.0291 \times \mathrm{T}+1.784 \times 10^{-5} \times \mathrm{T}^{2}$ \\
\hline
\end{tabular}




\begin{tabular}{|c|c|c|}
\hline Thermal Conductivity $(\mathrm{k})$ & $\mathrm{W} / \mathrm{m}-\mathrm{K}$ & $0.5047-0.0001 \times \mathrm{T}$ \\
\hline Melting Temperature $\left(\mathrm{T}_{\mathrm{m}}\right)$ & ${ }^{\circ} \mathrm{C}$ & 424.4 \\
\hline
\end{tabular}

The $\mathrm{sCO}_{2}$ turbomachinery is simulated as a zero-dimensional model based on their isentropic efficiencies $\left(\eta_{\text {isen }}\right)$.

The outlet enthalpies $\left(h_{\text {out }}\right.$ ) of the turbine and compressor are calculated using Eq. 1 and Eq. 2 respectively, where $h_{2 s}$ is a function of outlet pressure $\left(P_{\text {out }}\right)$ and inlet entropy $\left(s_{\text {in }}\right)$.

$$
\begin{gathered}
h_{\text {out }, \text { turb }}=h_{\text {in,turb }}-\left(h_{\text {in,turb }}-h_{2 s, t u r b}\right) \times \eta_{\text {isen,turb }} \\
h_{\text {out }, \text { comp }}=h_{\text {in,comp }}+\frac{h_{2 s, \text { comp }}-h_{\text {in,comp }}}{\eta_{\text {isen,comp }}}
\end{gathered}
$$

The heat exchanger code is one-dimensional in order to capture the nonlinear property variation of $\mathrm{sCO}_{2}$ along the length of the heat exchanger. The heat exchanger functions size the heat exchanger based on effectiveness $(\epsilon)$ using Eq. 3 or specifying the outlet temperature of either hot or cold stream.

$$
\epsilon=\frac{\dot{Q}}{\dot{Q}_{\max }}
$$

The actual amount of heat $\operatorname{transfer}(Q)$ is calculated from the given input of effectiveness and the $\dot{Q}_{\max }$ calculated based on Eq. 4.

$$
\dot{Q}_{\max }=\min \left(C_{\text {cold }}, C_{\text {hot }}\right) \times\left(T_{h, \text { in }}-T_{c, \text { in }}\right)
$$

The capacitance rate of the cold stream $\left(C_{\text {cold }}\right.$ in $\left.\frac{W}{K}\right)$ is calculated based on Eq. 5 and a similar equation can also be applied to calculate the hot stream capacitance rate $\left(C_{\text {hot }}\right)$.

$$
C_{\text {cold }}=m_{\text {cold }} \times \frac{h_{c, \text { in }}-h_{c, \text { out }, \text { max }}}{T_{c, \text { in }}-T_{c, \text { out }, \text { max }}}
$$

where the $h_{c, \text { out }, \max }=f\left(P_{c, \text { out }}, T_{c, \text { out }, \text { max }}\right)$ and $T_{c, \text { out }, \text { max }}=T_{h, \text { in }}$

The conductance $(U A)$ is calculated to all the heat exchanger zones using the NTU method [30] with the total conductance the sum of the conductance of all the zones. The heat duty of the heat exchanger is reduced if the minimum pinch temperature constraint is violated within the heat exchanger or any temperature crossover is detected. 
The steady-state mass and energy conservations are applied to all the components to calculate their outlet state properties from the inlet conditions, where $W$ is the mechanical power, $Q$ the heat power, $\dot{m}$ the mass flow rate and $h$ the enthalpy, while the subscripts in, out refer to the inlet and outlet respectively.

The recuperators are modelled based on effectiveness while the cooler and the primary heater are modelled based on the outlet temperature set point. The precooler is a direct air-cooled type with a pinch of $15{ }^{\circ} \mathrm{C}$ whilst the recuperator and the PHEX are compact Printed Circuit Heat Exchangers (PCHE). The cooling airflow to the precooler is adjusted to achieve the desired compressor inlet temperature.

The component models are integrated at the plant level in a flexible manner so that any plant configuration can be assessed. The plant solver estimates the tear stream values, calculate the error vector against the initial guess values and converges the solution using a non-linear iterative solver. The multi-variable Newton-Raphson iterative method is implemented and the Broyden algorithm is used for calculation of the Jacobian matrix.

In order to evaluate the plant off-design performance, compressor and turbine maps are needed. A centrifugal compressor is considered based on the Balje non-dimensionalised chart [31] for the size of the plant. The specific speed is calculated based on average density and isentropic enthalpy rise. The design non-dimensional specific speeds are 0.52 and 0.49 for the main compressor and recompressor, respectively. The performance maps were generated based on the empirical scaling approach that uses the modified flow and modified head coefficient of Sandia National Laboratory (SNL) test loop maps proposed by Dyreby et al. [32]. The modified flow coefficient is maintained the same as the SNL compressor i.e. 0.02971 and the load coefficient is calculated based on the method proposed by Dyreby et al. [32]. The shaft tip speed/rotational speed and the impeller exit diameter are calculated from the calculated flow and load coefficients. In order to calculate the surge compressor constraints, the minimum flow coefficient method is implemented. Liese et al. [33] proposed a ratio of surge point flow coefficient to the design flow coefficient of 0.7216 , which gives a surge flow coefficient of 0.02144 . Dyreby et al. [32], however, reported the SNL compressor surge flow coefficient is about 0.02 and since the optimisation Pareto front has to explore the complete operational regime, which can be reduced if the surge flow coefficient is increased, a minimum surge flow coefficient of 0.02 is selected for this work. The flow coefficients are calculated based on the compressor inlet conditions similar to Dyreby et al. [32]. A radial turbine is selected for this study considering the size of the plant as mentioned by Fleming et al. [34]. The turbine off-design models are according to Dyreby et al. [32], which scales the SNL test facility machine. 


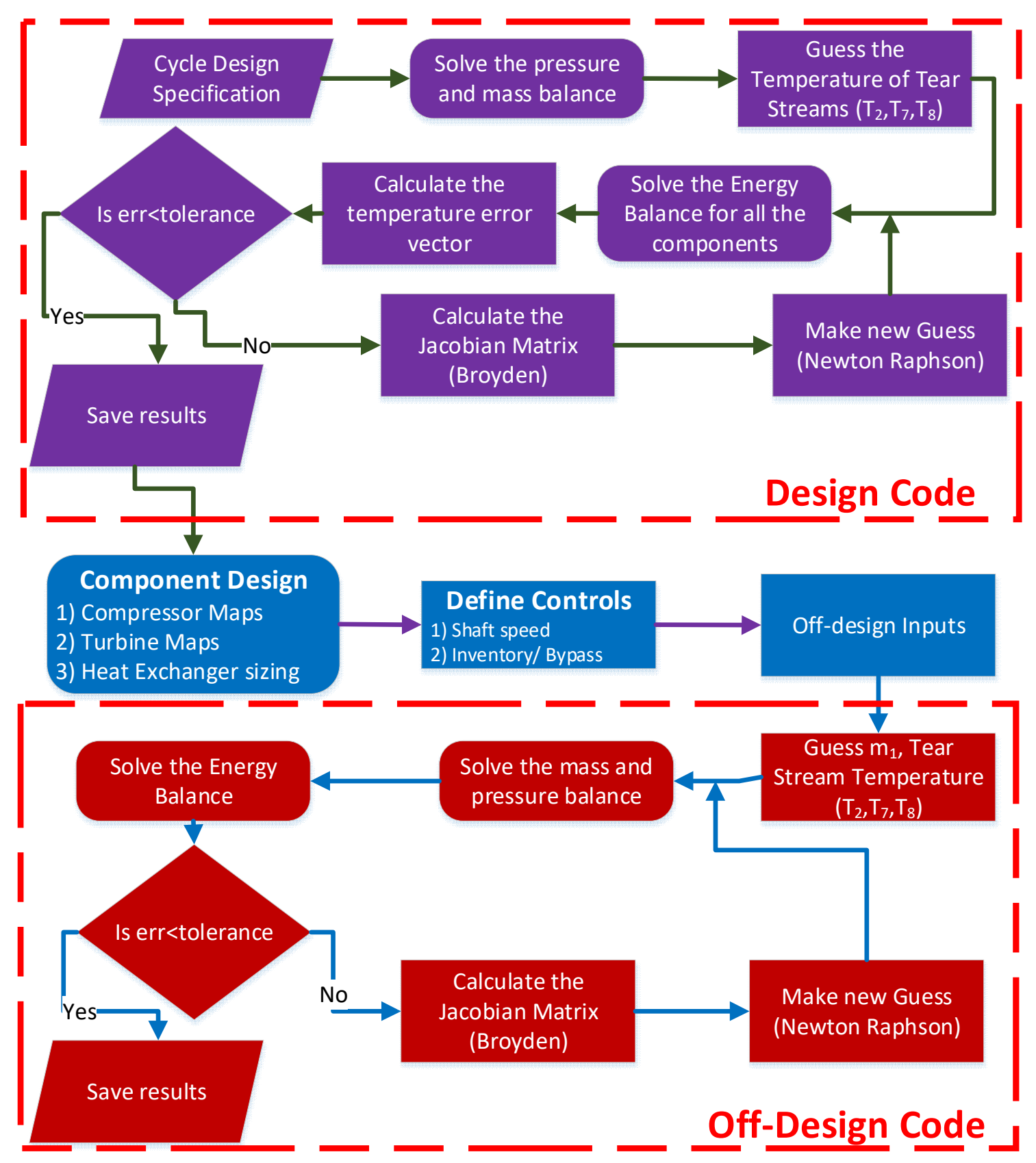

Fig. 3 Architecture of the plant simulation code

The heat exchanger off-design pressure drop $(D P)$ was scaled as per the procedure described by Dyreby et al. [35] (Eq. 6), and the heat exchanger conductance (UA) scaled using Panode [36] (Eq. 7). $\dot{m}$ refers to the mass flow rate, the subscripts $c, h$ refer to the cold and hot streams respectively while the subscript $r e f$ indicates the design/reference point value. Eq. 7 is derived from the Dittus-Boelter heat transfer correlation with an assumption of neglecting the thermal physical property variations from design to off-design conditions along the length of the heat exchanger. Tang et al. [37] used the Dittus-Boelter correlation for straight channel PCHE and validated the simulation results with experimental data published in Clementoni et al. [38]. Jiang et al. [39] proposed 0.809 as 
the Reynolds number scaling exponent in the Nusselt number calculation for low angle channels, however, this exponent is reduced to 0.721 for high angle channels. This work assumes a straight channel PCHE configuration; therefore the Reynolds number scaling exponent from the Dittus-Boelter correlation is used as used by Dyreby et al. [35] and Tse at al. [8].

$$
\begin{gathered}
D P=D P_{r e f} \times\left(\frac{\dot{m}}{\dot{m}_{r e f}}\right)^{1.75} \\
U A=U A_{r e f} \times\left(\frac{\dot{m}_{h} \times \dot{m}_{c}}{\dot{m}_{h, r e f} \times \dot{m}_{c, r e f}}\right)^{0.8} \times\left(\frac{\dot{m}_{h, r e f}^{0.8}+\dot{m}_{c, r e f}^{0.8}}{\dot{m}_{h}^{0.8}+\dot{m}_{c}^{0.8}}\right)
\end{gathered}
$$

The heat exchanger off-design code guesses the hot stream outlet temperature, matches the calculated conductance (UA) with the scaled UA, and iterates until the temperature converges. The heat duty of the heat exchanger is reduced if the minimum pinch temperature constraint is violated within the heat exchanger or any temperature crossover is detected. Fig. 3 shows the architecture of the plant level code that performs the process design, followed by the component sizing and the simulation of the off-design performance based on the type of controls defined.

The turbine shaft is connected to the generator and hence the speed was not controlled whilst the speed of the main compressor and recompressor were changed in order to meet the respective outlet pressure set points. Annual simulation are performed using System Advisory Model (SAM V2018.11.11) with the power block simulated as a user-defined power cycle (parametric table) for Daggett, California location.

\subsection{Modelling Assumptions}

The thermodynamic assumptions for cycle modelling are tabulated in Table 2. The heat exchanger pressure drop and the turbomachinery's mechanical loss were neglected. The heat exchanger was discretised to 15 zones for both design and off-design conductance calculations based on initial runs, which provides a trade-off between computational speed and accuracy, in order to capture the non-linear variation of isobaric specific heat. 


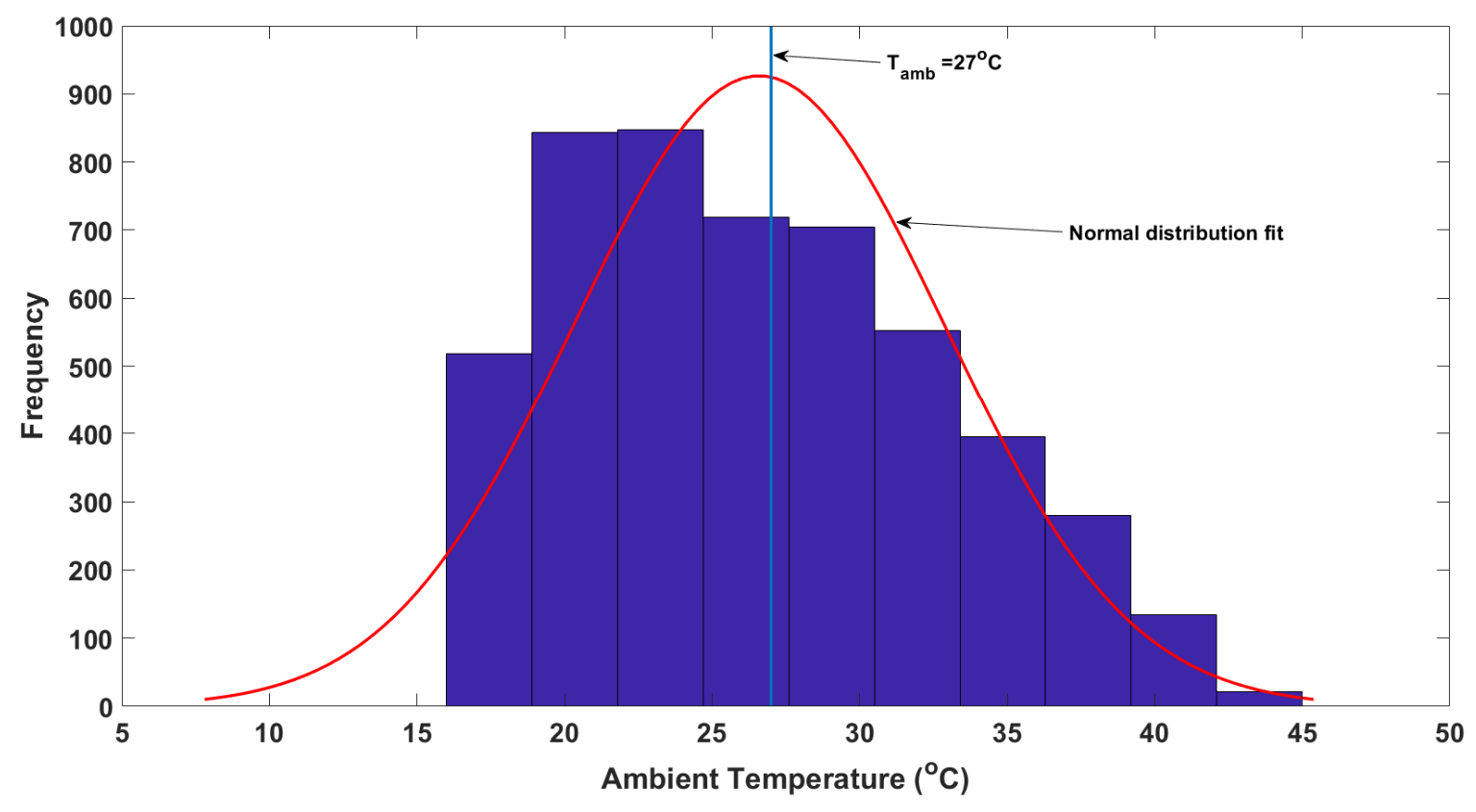

Fig. 4 Histogram of ambient temperature for Daggett, California (temperature higher than $17{ }^{\circ} \mathrm{C}$ )

Table 2 Thermodynamic modelling assumptions

\begin{tabular}{|l|c|c|}
\hline \multicolumn{1}{|c|}{ Description } & Unit & Value \\
\hline Turbine Isentropic Efficiency & $\%$ & 93 \\
\hline Main Compressor Isentropic Efficiency & $\%$ & 89 \\
\hline Recompressor Isentropic Efficiency & $\%$ & 89 \\
\hline Recuperator Effectiveness [40,41] & $\%$ & 98 \\
\hline Recuperator minimum pinch & ${ }^{\circ} \mathrm{C}$ & 5 \\
\hline High Pressure (Main Compressor Outlet) & bar & 250 \\
\hline Minimum Pressure & bar & 80 \\
\hline Split Fraction & - & 0.3 \\
\hline Compressor Inlet Temperature & ${ }^{\circ} \mathrm{C}$ & 42 \\
\hline Turbine Inlet Temperature & ${ }^{\circ} \mathrm{C}$ & 650 \\
\hline PHEX Approach Temperature & ${ }^{\circ} \mathrm{C}$ & 20 \\
\hline Pre-cooler Approach Temperature [42] & ${ }^{\circ} \mathrm{C}$ & 15 \\
\hline Design Ambient Temperature (Daggett, California) & ${ }^{\circ} \mathrm{C}$ & 27 \\
\hline
\end{tabular}

Daggett, California location is selected as an example to perform annual simulation and therefore the histogram of the temperature distribution is analysed in order to select the design ambient temperature. For lower ambient temperatures, the precooler coolant mass flow is reduced to maintain the main compressor inlet temperature above $32{ }^{\circ} \mathrm{C}$ so that condensation at the compressor inlet is avoided. In order to select the design ambient temperature, therefore, ambient temperatures below $17{ }^{\circ} \mathrm{C}$ are not considered due to the $15{ }^{\circ} \mathrm{C}$ precooler approach. The histogram of the reduced dataset with a normal distribution fit to aid in selecting the optimal temperature is plotted in Fig. 4 from this analysis a design ambient temperature of $27^{\circ} \mathrm{C}$ is selected. This CIT is approximately $2.5^{\circ} \mathrm{C}$ higher than the optimal temperature for the Daggett, California location proposed in [43] through extrapolation 
of design and off-design results for estimating the annual performance. However, it should be noted that the proposed optimal value could be sensitive to the assumptions in that study and a higher CIT is conservative.

\subsection{Optimising the Off-design Condition}

In this study, both single and multi-objective optimisations are performed. Firstly optimised power block performance data is modelled as a look-up table for annual simulation. Then, since the focus of this study is to compare the annual performance difference when operating the power block in either maximum efficiency or maximum power mode, two further sets of single-objective optimisations are performed to maximise the objective functions (net power/ efficiency) for each data point of the look-up table. The algorithm optimises the primary process variables such as the main compressor inlet pressure $\left(\mathrm{P}_{1}\right)$, main compressor outlet pressure $\left(\mathrm{P}_{2}\right)$ and split fraction $\left(\mathrm{m}_{11} / \mathrm{m}_{9}\right)$, subject to the main compressor and recompressor surge constraints. The objective function is not continuous in the optimisation search space owing to the discontinuous constraints, so the faster nonlinear line-search method (Sequential Quadratic Programming, SQP) often fails to find the global optimal solution and as a result, a heuristic method has been incorporated for optimisation. Considering the computational effort of heuristic algorithms, an initial attempt was made to use a hybrid algorithm, which runs the heuristic algorithm for a fixed number of generations and initialises the SQP to find the global optimum faster. Nonetheless, the number of generations of the heuristic algorithm decides the ability to reach the global optimum and therefore the heuristic genetic algorithm (GA) was chosen for this study.

A multi-objective optimisation was performed to explore the complete Pareto front for changes in the boundary conditions so that the trend of the control variables can be envisaged. A Non-dominated Sorting Genetic Algorithm (NSGA-II) [44] is used which maximises the net efficiency and net power by optimising the power cycle control variables. Table 3 shows the range of the optimisation parameters used for both single and multi-objective optimisation.

Multi-objective optimisation optimises many objective functions simultaneously subject to equality and nonequality constraints. An individual $\mathrm{X}(\mathrm{a})$ is said to be a dominant solution if $\mathrm{X}(\mathrm{a})$ is better than other solutions in all objective functions or $\mathrm{X}(\mathrm{a})$ is strictly better than other solutions in at least one objective subjected to the constraints [45]. A non-dominated Sorting Genetic Algorithm (NSGA II) was coded in MATLAB ${ }^{\circledR}$ [46-48] to perform the optimisation study and the flowchart of the code is similar to [3]. The only difference is that the process design is performed prior to the optimisation loop and the off-design model returns the objective functions and constraints. The number of population and the number of generations are selected between $15-30$ times the 
number of variables depending on the number of constraints. A higher number of population and generations are used when the problem is more constrained in order to guarantee convergence to the global optimum solution.

Table 3 Variable ranges of parameters considered in optimisation

\begin{tabular}{|l|l|l|l|}
\hline \multicolumn{1}{|c|}{ Variable } & \multicolumn{1}{c|}{ Unit } & \multicolumn{1}{c|}{ Min bound } & \multicolumn{1}{c|}{ Max bound } \\
\hline Minimum Pressure & bar & 74 & 100 \\
\hline Maximum Pressure & bar & 150 & 250 \\
\hline Split Ratio & - & 0.15 & 0.45 \\
\hline Molten Salt Mass flow* & \% of design flow rate & 90 & $110 \%$ \\
\hline
\end{tabular}

*mass flow rate was fixed to the desired value in section 6.2 and 7

The NSGA-II algorithm optimises the cycle minimum/maximum pressure, split ratio and molten salt mass flow rate with the objective of maximising the cycle net efficiency and net power. The main and recompressor shaft speeds are controlled to achieve the desired outlet pressure set points. The turbine shaft speed is maintained at its design speed as it is connected to the synchronous generator through a gearbox. Implementation of a Variable Frequency Drive (VFD) for the turbine can be costlier as its shaft power is greater than the compressor shaft power. In off-design, once the cycle minimum and maximum pressures are set then the $\mathrm{sCO}_{2}$ mass flow rate is dictated by the compressor-turbine matching using the performance map of respective components. The compressor surge constraints are checked, however, no surge margin is implemented in order to explore the complete Pareto front so that the Pareto front can be trimmed to any given surge margin. Selection of surge margin also requires consideration of the transient load ramping behaviour of the plant to ensure safe operation. By optimising these four process variables (Table 3), the cycle is able to simulate inventory control, TIT control and split fraction control by optimally choosing the variables. Nonetheless, this work does not model either throttling control, which requires an additional valve to throttle the turbine inlet pressure, or the turbine bypass control. In order to understand the power block characteristics for different ambient temperatures, the CIT has to be fixed although it is actually dictated by the off-design conductance of the precooler for any given cold and hot streams state boundary condition. The mass flow rate of the cold stream is therefore controlled in order to achieve the desired CIT, ensuring the precooler pinch constraints are not violated.

\subsection{Solar Field}

The annual simulation is performed using the System Advisory Model (SAM V2018.11.11), which designs a heliostat field layout optimised for the selected location of Dagget, California. A solar multiple of 2.8 and 14 hours of TES are used in this study [42]. SAM calculates the hourly optical efficiency and evaluates the energy absorbed by the HTF considering both the receiver and piping losses. SAM supplies the heat to the power block 
to meet the dispatch requirement storing any remaining heat in the TES. Dispatch optimisation is not turned-on and the dispatch method, time of delivery factors and weekly schedule pattern are all retained at the default values for this study, although they could influence the total number of start-ups. The user-defined power block parametric table defines the power output based on the heat supplied to the power block for the changes in the boundary conditions such as ambient temperature, MSIT and molten salt mass flow rate (MSFR). This parametric table is different for each operational strategy so that the only supplies the heat demanded of the power block for the given boundary conditions in order to produce the power output required by the dispatch mode at each time step.

Table 4 Solar field model assumptions for costs estimation [51]

\begin{tabular}{|c|c|c|c|c|c|}
\hline Performance factors & Unit & Value & Finance factors & Unit & Value \\
\hline Thermal Energy Storage & $\$ / \mathrm{kW}_{\text {th }}$ & 15 & Inflation rate & $\%$ & 3 \\
\hline Heliostat Field Cost & $\$ / \mathrm{m}^{2}$ & 75 & Real discount rate & $\%$ & 5.5 \\
\hline Site Improvement cost & $\$ / \mathrm{m}^{2}$ & 10 & Contingency & $\%$ & 10 \\
\hline Land cost & $\$ / \mathrm{m}^{2}$ & 2.471 & Analysis Period & Years & 35 \\
\hline
\end{tabular}

Since the purpose of the annual simulation is to compare the two different operational strategies, the cost of the $\mathrm{sCO}_{2}$ power block is fixed for both cases (design point is fixed). The value of $925 \$ / \mathrm{kW}_{\mathrm{e}}$ is assumed in our study as suggested by Schmitt et al. [42]. Scaling exponents of 0.7 and 0.0113 are used to calculate the cost of the solar receiver and the tower, respectively. The fixed cost by capacity of $66 \$ / \mathrm{kW}-\mathrm{yr}$ and the variable generation cost of 3.5 \$/MWh are considered. All of the financial assumptions are tabulated in Table 4 [51].

\section{Model Validation}

The design code is validated against the data reported in Kulhánek and Dostál [49] by setting up an optimisation that uses sequential quadratic program algorithm in MATLAB. The optimisation algorithm maximises the efficiency by varying the split fraction and cycle pressure ratio. All the heat exchangers are discretised to 15 zones. Performance comparison is performed for two different turbine inlet temperatures (i.e. 600 and $650{ }^{\circ} \mathrm{C}$ ) for a maximum cycle pressure of 250 bar, CIT of $32{ }^{\circ} \mathrm{C}$, compressor efficiency of $89 \%$, recuperator effectiveness of $95 \%$ with a minimum pinch of $5{ }^{\circ} \mathrm{C}$. Kulhánek reported a turbine efficiency of $93 \%$, however, Turchi et al. [50] repeated the same boundary conditions for validation purposes and commented that a turbine efficiency of $90 \%$ closely reproduces Kulhánek results, therefore $90 \%$ turbine efficiency is used in this work. The results match with the reported values in Turchi et al. [50], however, a maximum relative error of $0.7 \%$ was observed against Kulhánek results for a TIT of $650{ }^{\circ} \mathrm{C}$ (Table 5). 


\begin{tabular}{|c|c|c|c|c|}
\hline $\begin{array}{c}\text { Turbine Inlet } \\
\text { Temperature } \\
\left({ }^{\circ} \mathrm{C}\right)\end{array}$ & $\begin{array}{c}\text { Efficiency (\%) } \\
\text { (Turchi) }\end{array}$ & Efficiency (\%) & \multicolumn{2}{|c|}{ This Study } \\
\cline { 4 - 5 } & (Kulhánek) & Efficiency (\%) & Split Fraction \\
\hline $\mathbf{6 0 0}$ & 48.31 & 48.3 & 48.32 & 0.337 \\
\hline $\mathbf{6 5 0}$ & 50.24 & 49.9 & 50.25 & 0.333 \\
\hline
\end{tabular}

In order to verify the off-design code, a $30 \mathrm{MW}_{\mathrm{e}}$ power cycle was modelled in the MATLAB ${ }^{\circledR}$ in-house code and the recuperator conductance was provided as an input to the Dyreby FORTRAN code for validation. The main compressor shaft speed was fixed during off-design simulation as the Dyreby code assumes that the turbine and main compressor shafts are connected. The efficiency and process temperature results obtained from the two simulation codes are compared for both design CIT of $42{ }^{\circ} \mathrm{C}$ and off-design CIT of $55^{\circ} \mathrm{C}$ and a maximum the relative percentage error of $0.1 \%$ is observed. Since this verification was performed against the Dyreby code, all the component modelling assumptions are known, therefore, the source of discrepancy is due to the numerical tolerance of the nonlinear equation solver.

\section{Results and Discussion}

\subsection{Design Performance}

The split fraction and the compressor inlet pressure cannot be optimised to maximise the efficiency as they reduce the cycle specific power and increase the size of the recuperator, therefore a cycle minimum pressure of 80 bar and split fraction of 0.3 are selected for this study. The corresponding design performance of the recompression cycle is tabulated in Table 6 where the differential temperature across the PHEX is about $150{ }^{\circ} \mathrm{C}$, the specific work is $\sim 153 \mathrm{~kJ} / \mathrm{kg}$ and the recuperator conductance is $8.8 \mathrm{MW} / \mathrm{K}$ whilst PHEX conductance is $3 \mathrm{MW} / \mathrm{K}$.

Table 6 Design performance of recompression cycle

\begin{tabular}{|l|c|c|}
\hline \multicolumn{1}{|c|}{ Description } & Unit & Value \\
\hline Net Power & $\mathrm{MW}$ & 30.66 \\
\hline Net Efficiency & $\%$ & 49.02 \\
\hline$\Delta \mathrm{T}$ across PHEX $\left(\mathrm{sCO}_{2}\right.$ side) & ${ }^{\circ} \mathrm{C}$ & 149.7 \\
\hline Recuperator UA (LTR+HTR) & $\mathrm{MW} / \mathrm{K}$ & $8.8(3.5+5.3)$ \\
\hline Primary Heat Exchanger UA & $\mathrm{MW} / \mathrm{K}$ & 3.0 \\
\hline
\end{tabular}

\section{Multi-Objective Optimisation for Off-Design Performance}

\subsection{Effect of Ambient Temperature Variation}


Fig. 5 shows the Pareto fronts for different CITs, where it can be seen that both the net efficiency and the net power of the power block significantly decreases at higher CIT's. The net power fraction is the off-design net power output normalised with the design net power and this can exceed one depending on the boundary conditions (Table 3). No constraints on the maximum net power fractions were imposed to explore the complete Pareto front, however, the turbine peak power can limit this, in which case the Pareto front can be shortened. The dotted lines in the Fig. 5 show the Pareto fronts, which have an additional upper MSOT constraint of 2\% from its design value ( $~ 5.4 \%$ reduction of the thermal storage capacity). It can also be seen from Fig. 5 that by limiting the MSOT close to its design value, the maximum net power of the Pareto fronts are unaffected, whilst the maximum efficiency cases are negatively affected with the amount of change increasing with the CIT. The CIT of $40{ }^{\circ} \mathrm{C}$ is less influenced by the MSOT constraint (design CIT $=42{ }^{\circ} \mathrm{C}$ ), however, the impact is more pronounced as the CIT increases. In Fig. 6, it is possible to see the MSOT behaviour across the Pareto front for different CITs. The MSOT constrained Pareto fronts are sub-optimal Pareto of the base case and therefore they limit the maximum value of the main compressor inlet pressure (shown in Fig. 7 (a)) and so also the pressure ratio. The efficiency reduces by $0.8 \%$ points at $55^{\circ} \mathrm{C} \mathrm{CIT} \mathrm{by} \mathrm{constraining} \mathrm{the} \mathrm{MSOT.} \mathrm{For} \mathrm{CIT}=40^{\circ} \mathrm{C}$, however, the majority of the MSOT curve (Fig. 6) is below the imposed limit of $102 \%$ of the design value and thus both control strategies, with or without MSOT limiting, are less affected as can be seen by the curves for CIT $=40{ }^{\circ} \mathrm{C}$ in Fig. 5 .

From Fig. 7 (a), it is worth noting that the main compressor (MC) inlet pressure reached the minimum bound when maximising the net power while the MC inlet pressure increases as the compressor inlet temperature increases in order to achieve the maximum cycle efficiency. Maximising the net power output from the power cycle for different compressor inlet temperatures always tends to increase the pressure ratio as the minimum pressure reaches the lower bound and maximum pressure reaches the upper bound as shown in Fig. 7 (a). 


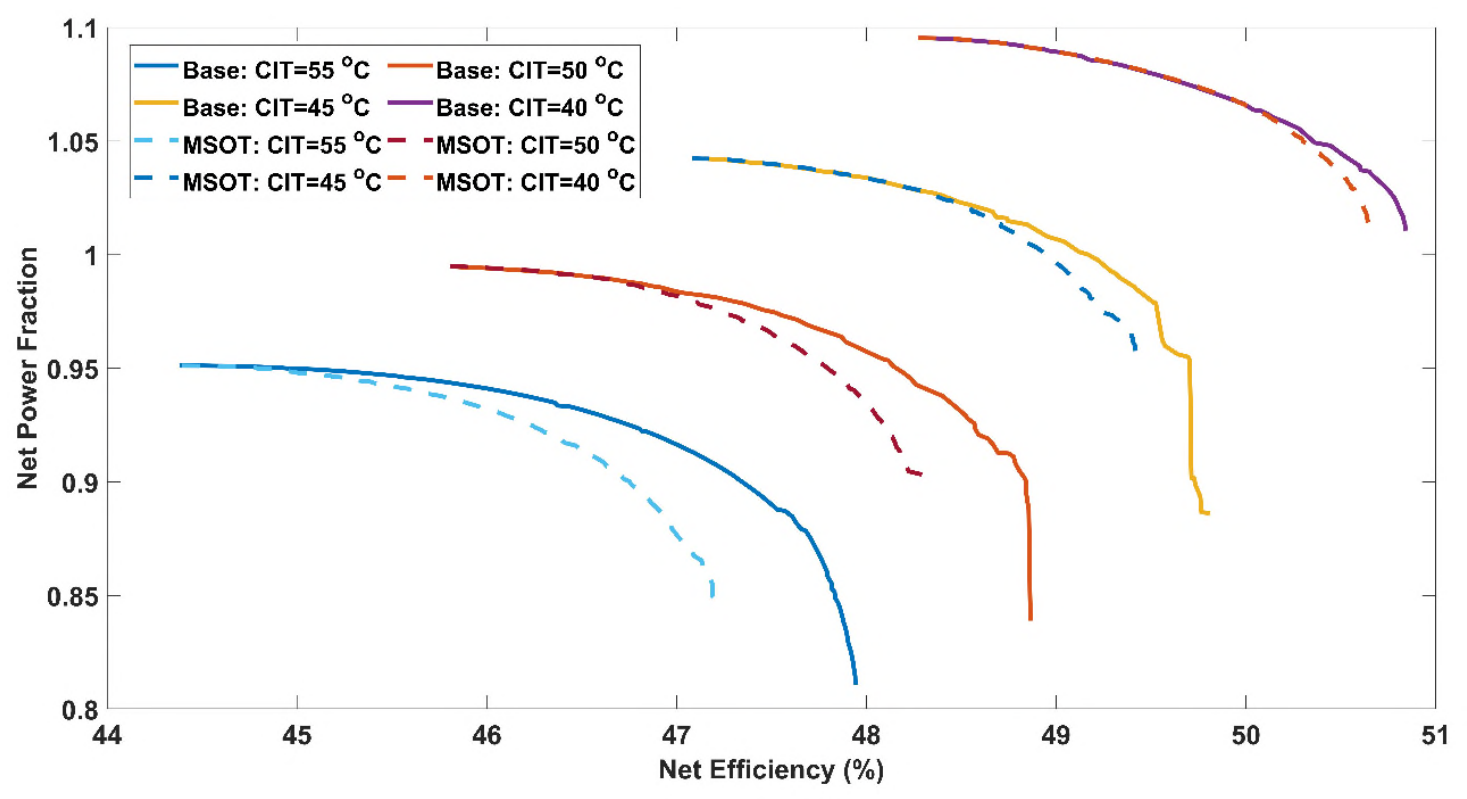

Fig. 5 Pareto fronts of recompression cycle for different CIT (continuous lines represent the Pareto fronts without limiting the MSOT, dashed lines show the MSOT limiting cases)

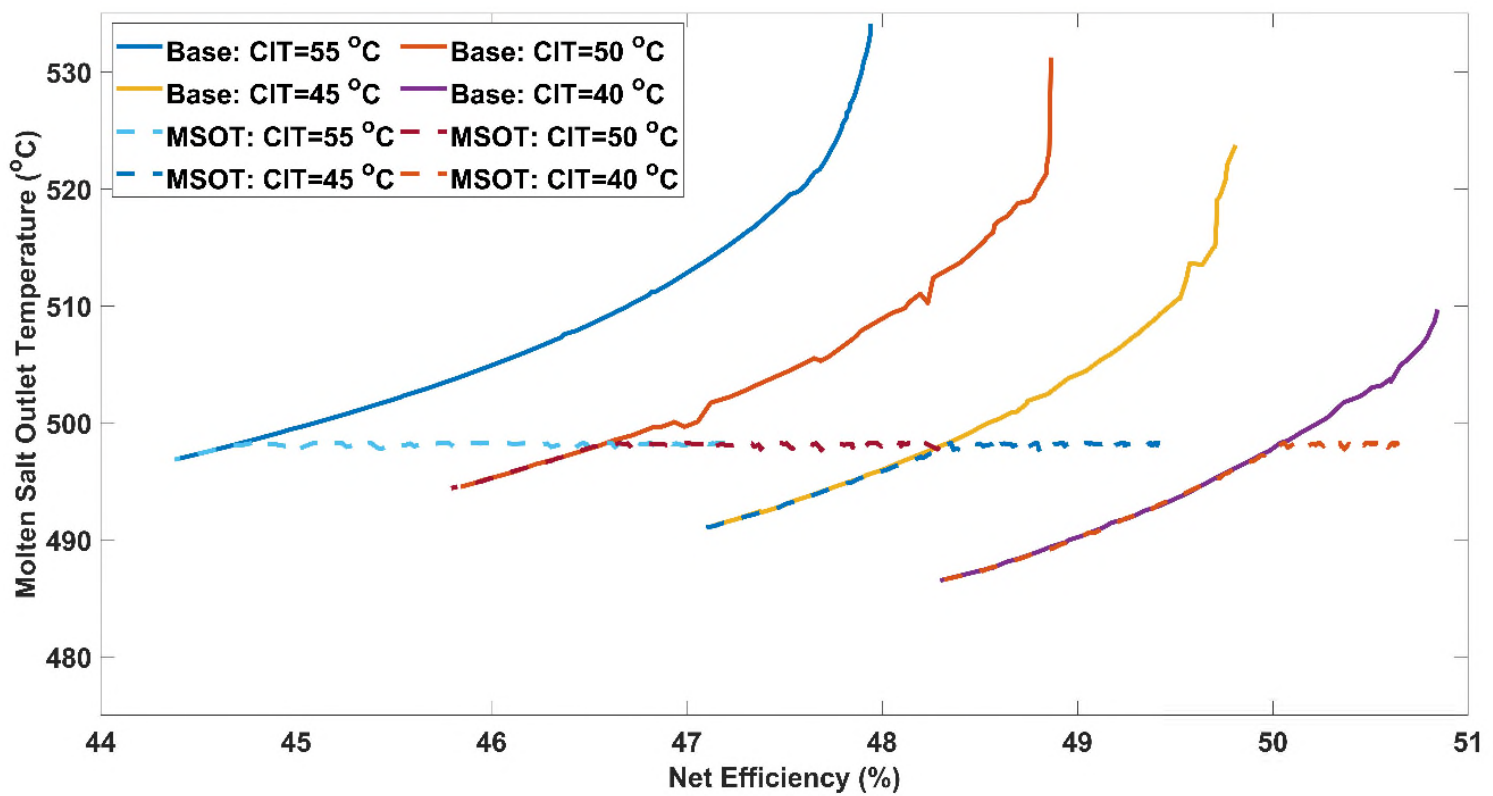

Fig. 6 MSOT with respect to the net efficiency across the Pareto front (shown in Fig. 5) for different CIT (Continuous lines represent the Pareto fronts without limiting the MSOT, dashed lines show the MSOT limiting cases) 


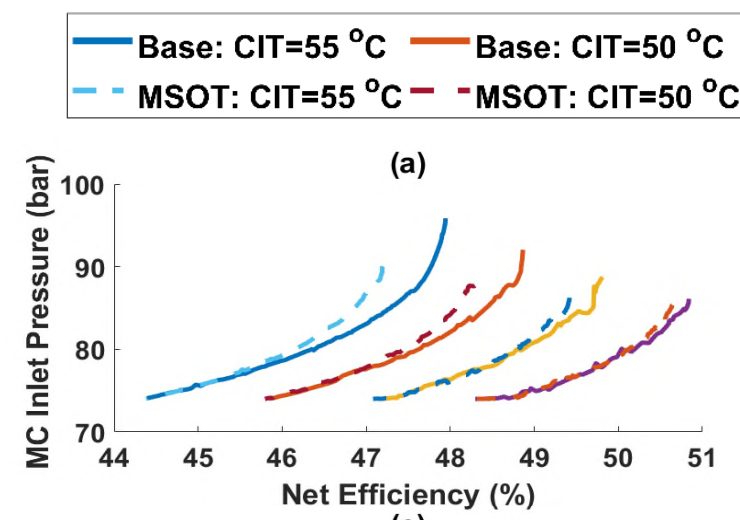

(c)

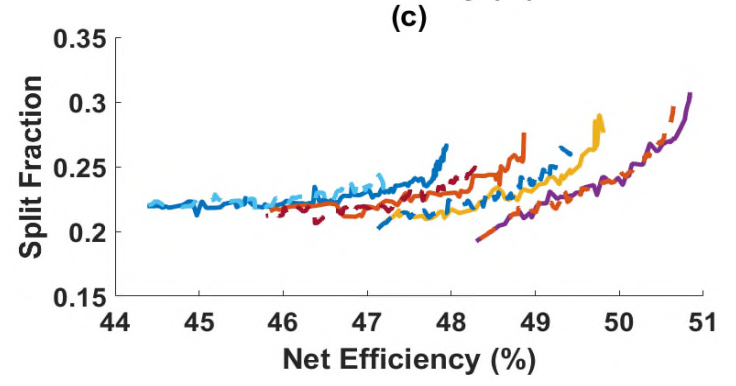

\section{Base: $\mathrm{CIT}=45^{\circ} \mathrm{C}$-Base: $\mathrm{CIT}=40^{\circ} \mathrm{C}$}

-MSOT: $\mathrm{CIT}=45^{\circ} \mathrm{C}-{ }^{-M S O T}$ : $\mathrm{CIT}=40^{\circ} \mathrm{C}$

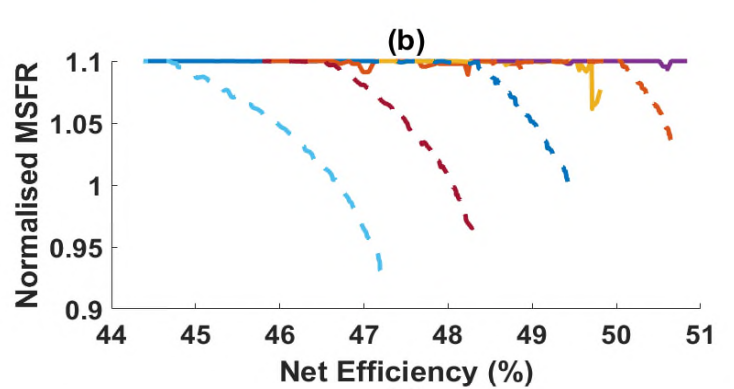

(d)

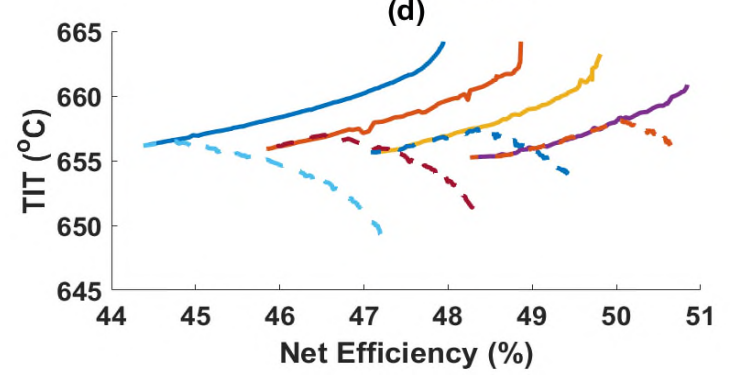

Fig. 7 Process variables with respect to the net efficiency across the Pareto front (shown in Fig. 5) for different

CIT: a) Main Compressor Inlet Pressure, b) Molten Salt Inlet Flow Rate, c) Split Fraction, d) Turbine Inlet

\section{Temperature}

The split ratio of the mass flow rate towards the recompressor is minimum when maximising the net power whilst it increases when maximising the efficiency (Fig. 7 (c)). It is also worth noting that the difference in the split fraction between the maximum efficiency and maximum net power cases reduce as the CIT increases (Fig. 7 (c)). The split fraction reduces when maximising the efficiency at a higher CIT because the compressor inlet shifts away from the critical point, therefore, the real gas effect is minimal. Consequently, the difference between the cold and hot stream isobaric specific heat also reduces and RCBC approaches towards SRBC configuration (single recuperator). This had been already observed by Carstens et al. [52] i.e. split fraction reduces at a higher CIT, nonetheless, the split fraction corresponding to the maximum net power case is not notably affected for different CITs from which it can be concluded that split fraction control is less significant when maximising the net power. Increasing the CIT also increases the compressor outlet temperature (compressor inlet conditions move away from the critical point) which also increases the LTR hot stream outlet temperature. This also reduces the capacitance difference between hot and cold streams of LTR, consequently, the split fraction reduces with increase in CIT for maximum efficiency cases. 
The molten salt mass flow rate reached $110 \%$ (maximum bound) across the complete Pareto front. Although the TIT tends to increase with efficiency for the base case, it does not when the MSOT is constrained (Fig. 7 (d)). The maximum TIT occurs neither in the maximum net power case nor in the maximum efficiency case. The molten salt flow rate also reduces to increase the maximum efficiency as the CIT increases.

Increases in CIT also increase the compressor inlet volumetric flow rate (for the same mass flow and fixed flow area) and changes the local Mach number (speed of sound changes), consequently the operating point shifts. To minimise the shift of compressor off-design point in the performance map at a higher CIT, the inlet pressure has to increase to compensate for the drop in density. However, this does not return the compressor operating point back to the design as the local Mach number also shifts with the increase in CIT owing to the change in the speed of sound. Nevertheless, it has been observed that the compressor inlet volumetric flow is higher than the design point volumetric flow at higher CIT when the cycle is optimised for maximum efficiency. This observation is in line with Bennett et al. [53] and the trend is expected to depend on the shape of the compressor map.

Maximising the efficiency of a closed-loop Brayton cycle for a given TIT and CIT tends to lower the pressure ratio in a way that minimises the impact on the turbomachinery efficiencies, while the overall recuperation effectiveness is unaffected. It has also been observed that the compressor outlet pressure always tends to reach the maximum bound for both the cases (maximising the net power/maximising the net efficiency), therefore the main compressor inlet pressure variation can also be interpreted as the inverse of the compressor pressure ratio. The compressor inlet pressure can be increased (thus reducing the pressure ratio) to compensate for the reduction in density owing to the increase in CIT, and by doing so the inlet volumetric flow can be maintained close to the design value. Thus, the compressor efficiency is only affected by the changes in the non- dimensional speed and local Mach number. From the optimisation results, it has been observed that the mass flow rate reduces and also the split fraction reduces at a higher CIT as shown in Fig. 7 (c). Reduction in the cycle pressure ratio when maximising the efficiency also increases the turbine exhaust temperature for a given TIT, which also increases the cold stream inlet temperature to the PHEX owing to higher recuperation of the HTR, increasing MSOT. 

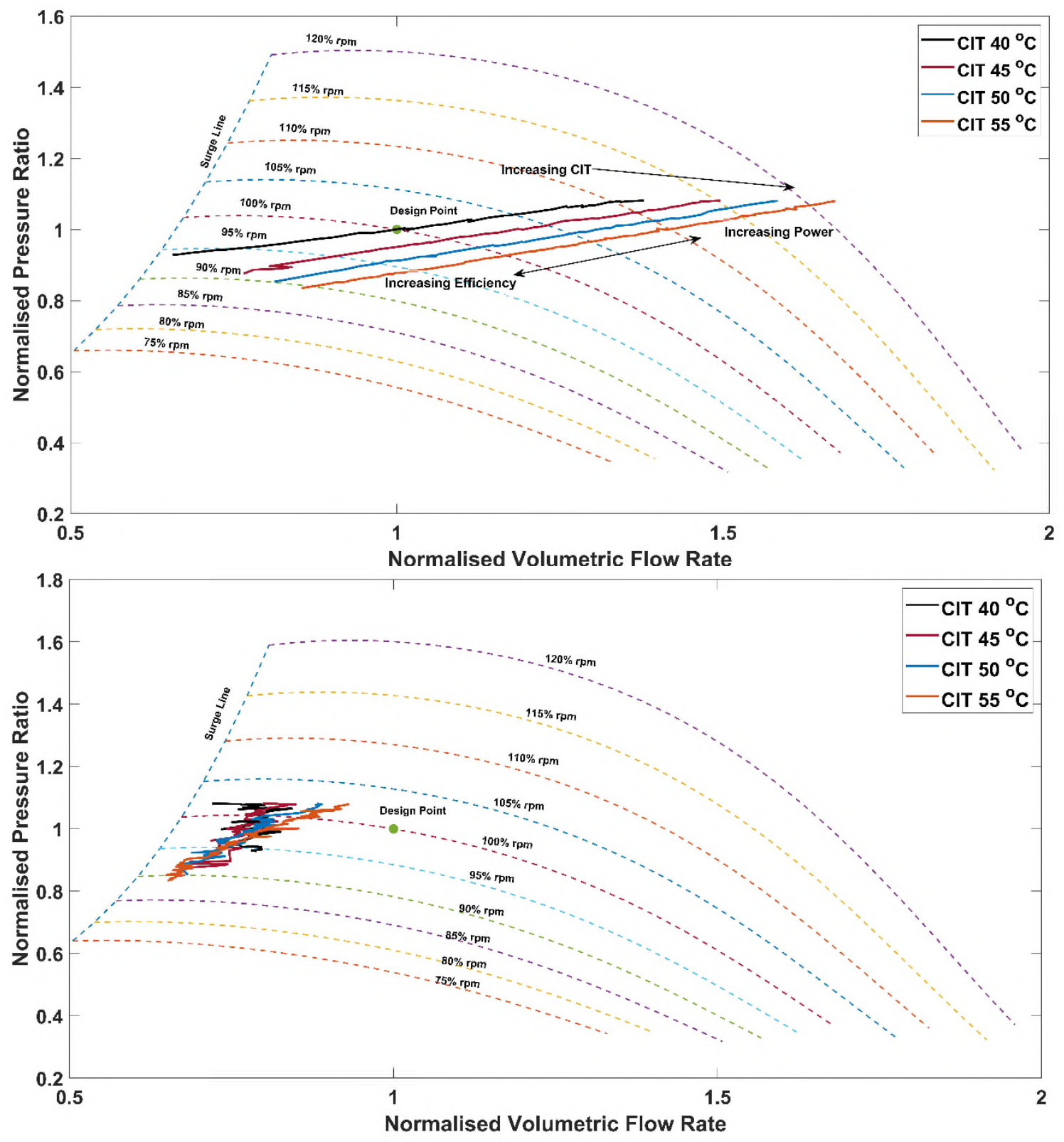

Fig. 8 Compressor operating point across the Pareto front (shown in Fig. 5) for different CIT; Top) Main Compressor, Bottom) Recompressor (dashed lines represent the compressor map while the operating points across the Pareto front are plotted as continuous lines)

It is clear, therefore, that the cycle pressure ratio drops at a higher CIT when maximising the cycle efficiency and the magnitude varies based on the turbomachinery performance map. Consequently, the turbine exhaust temperature typically tends to increase for the constant turbine inlet temperature, though the latter is not strictly true as shown in Fig. 7 (d). 
This increase in TET also increases the cold stream inlet temperature to the PHEX, therefore the MSOT increases. The MSOT increases by $46{ }^{\circ} \mathrm{C}$ at $55^{\circ} \mathrm{C}$ CIT and this implies that the TES storage capacity reduces by $25.1 \%$ if the operation is continued until the cold tank temperature equalises with MSOT and the duration depends on the instantaneous cold tank inventory.

The compressor operating points across the Pareto fronts for different CIT are plotted on the compressor map as Fig. 8 to visualise the operational characteristics. The main compressor volumetric flow changes significantly across the Pareto front whilst the recompressor volumetric flow changes are minimal. This is because the density variation at the main compressor inlet changes significantly near the critical point. At higher CIT's, the main compressor volumetric flow increases with the falling pressure ratio when maximising the efficiency. When maximising the power, the volumetric flow to the main compressor increases with the maximum cycle pressure ratio. It has to be noted that a compressor over-speed limitation is not included as a constraint in this optimisation in order to explore the complete Pareto front, however, in reality the maximum net power is capped by the overspeed limit. If the main compressor shaft is connected to the turbine, which runs at a constant speed, the reduction in maximum power at higher CIT is higher than the indicated values here. On the other hand, the compressor surge margin affects the maximum efficiency of the cycle, particularly at CIT's lower than the design value. The increase in the volumetric flow is not significant in the recompressor when the CIT is higher than $40{ }^{\circ} \mathrm{C}$, therefore, the main compressor operational speed and surge limits are crucial in order to realise the maximum power and maximum efficiency, respectively. Since the cycle minimum pressure and the split fraction at the design do not maximise the power cycle efficiency, the recompressor operates away from the design point. This is mainly driven by the lower split fraction across the Pareto front than the design value of 0.3 . The design split fraction is only achieved in the Pareto front when maximising the efficiency for a CIT of $40{ }^{\circ} \mathrm{C}$ (Fig. 7 (c)). The corresponding cycle minimum pressure (Fig. 7 (a)) is slightly higher than the design value (i.e. 80 bar) by $\sim 5$ bar with a significant reduction in the recompressor inlet temperature $\left(\sim 30^{\circ} \mathrm{C}\right)$, owing to the recuperation maximising. This increases the recompressor inlet density and consequently moves the operating point away from the design. Sizing the recompressor for maximum cycle design efficiency eliminates this difference when operating the plant in maximum efficiency mode. However, the selection of optimal split fraction and cycle minimum pressure at the design plays a critical role in the recompressor off-design operation when the plant needs to run in a combination of maximum power and efficiency modes. Although the recompressor speed control helps to bring the operating point close to the design point at a higher ambient temperature when the efficiency is maximised, it doesn't benefit for a lower ambient temperature. Other approaches such as $2 \times 50 \%$ recompressor, inlet guide vane and compressor 
hot-recirculation can aid in handling a large variation in the volumetric flow rate at lower ambient temperatures, however, the latter option can penalties the efficiency of the system.

The compressor inlet pressure required to match the compressor inlet density at the design is calculated for every CIT (Fig. 9). Matching the compressor inlet density to the design density doesn't guarantee the same volumetric flow at the compressor inlet as the optimal mass flow rate and split fractions are different for every CIT and therefore, the compressor inlet pressure required to match the design volumetric flow is also plotted in Fig. 9. Nevertheless, it is worth highlighting that the change in the mass flow and split fraction are not known prior to perform a complete optimisation. The estimated pressure based on a constant volumetric flow rate at the compressor inlet is higher when the CIT is high. This implies that the optimised volumetric flow rate from NSGAII was higher than the design value. On the other hand, the optimised volumetric flow rate at the main compressor inlet was slightly lower than the design value at a lower CIT.

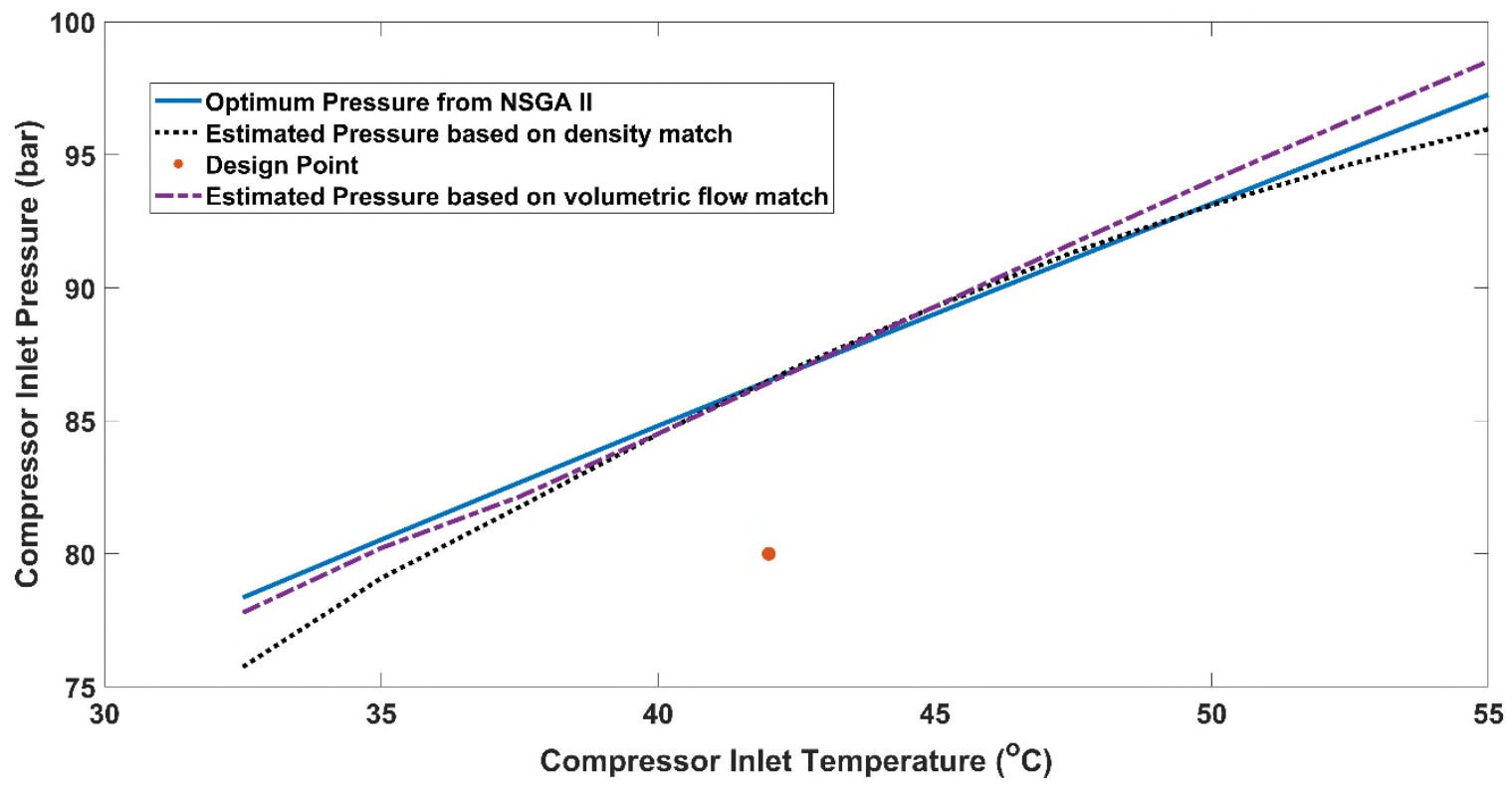

Fig. 9 Comparison of estimated compressor inlet pressure against the optimised pressure when maximising the

$$
\text { efficiency }
$$

However, the estimated pressure, based on the assumption of constant density predicts lower pressure (higher volumetric flow rate) at very high CIT, although it is relatively similar to the optimal value until the CIT is $50{ }^{\circ} \mathrm{C}$. Nonetheless, this approach deviates significantly from the optimal value at a lower CIT. This deviation occurs owing to the changes in fluid properties which affects the Mach number and the magnitude can vary based on the shape of the compressor map. It is worth highlighting that the compressor inlet pressure chosen for this study was 
not an optimal value that maximises the efficiency at the design CIT since the design pressure selection is always a trade-off between maximising net power and efficiency.

\subsection{Effect of Molten Salt Flow Rate Variation}

Since the MSIT and CIT are unaffected from the design value, the speed of sound is unaffected, the compressor and turbine operating point can be kept close to the design value for an ideal gas closed-loop Brayton cycle by lowering the system inventory and keeping the cycle pressure ratio constant. For an ideal gas, this infers that the system pressure drops in proportion to the mass flow reduction in order to keep the density constant [26,54]. Since changes in the system pressure do not affect the specific heat for monotonic ideal gases, the efficiency and the specific power of the cycle can be maintained close to the design value for a large plant turndown ratio (neglecting the variation of the heat exchanger pressure drop and heat transfer coefficient due to changes in the Reynolds number) [26]. For supercritical fluids, the pressure significantly affects the heat capacity, heat transfer coefficient etc. and the relationship between pressure and density is non-linear. Furthermore, the speed of sound is also a function of the compressibility factor which is also sensitive to pressure [55].

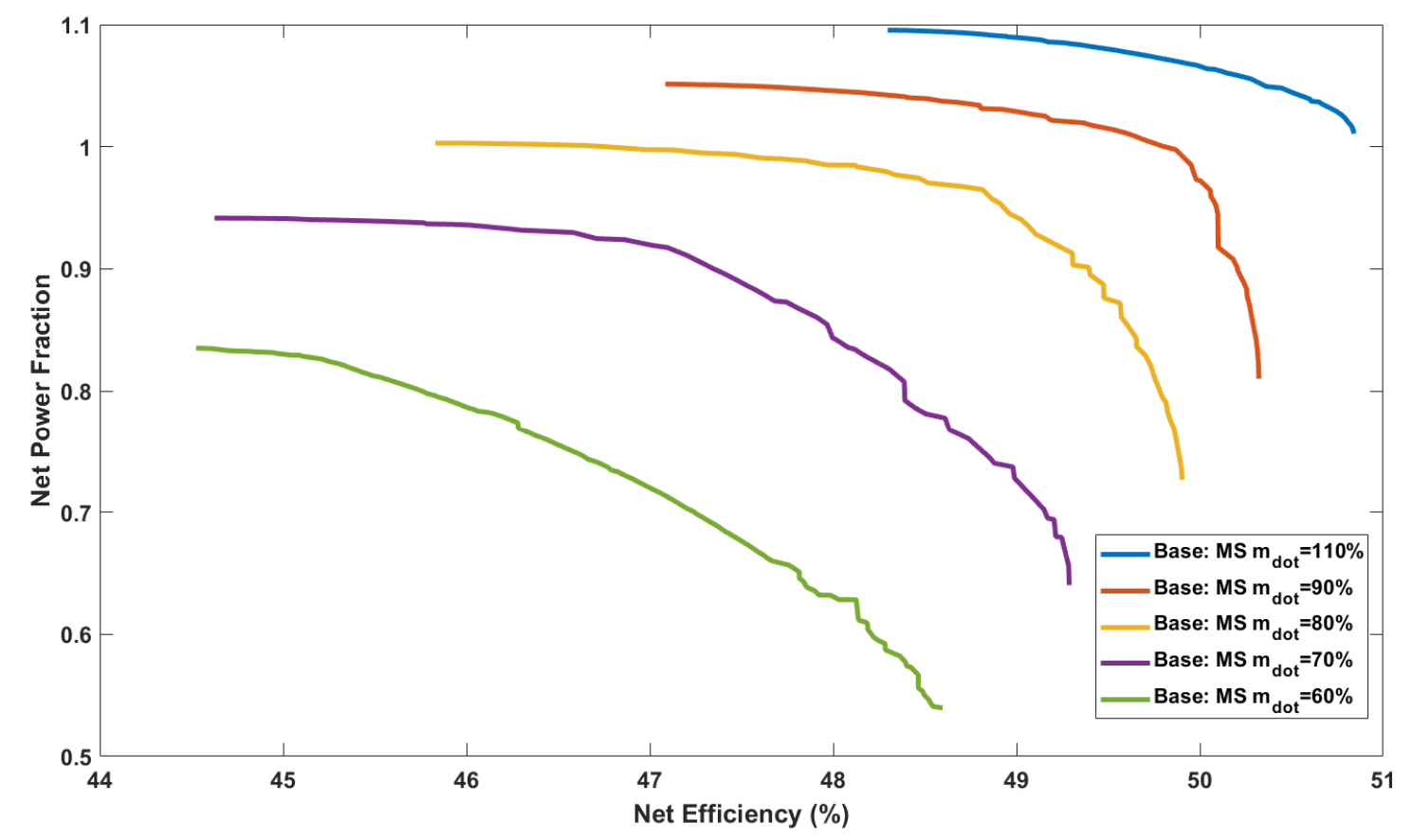

Fig. 10 Pareto fronts of recompression cycle for different MSFR (The percentages are referred to the design MSFR)

The off-design Pareto fronts for the variation of the fractional MSFR is shown in Fig. 10 at the CIT of $40{ }^{\circ} \mathrm{C}$. It can be observed that the net power can be about $83.5 \%$ of the design value when the molten salt mass flow rate is 
$60 \%$ of the rated flow by operating the power block in the maximum power mode. On the other hand, this reduces the efficiency to $44.5 \%$, which can be increased to $48.6 \%$ with a sacrifice in the net power to about $54 \%$ of the design value. This indicates that the degree of freedom for operating the $\mathrm{sCO}_{2}$ power block is larger and the efficiency and net power can be changed significantly depends on the operating point dictated by the control strategy.

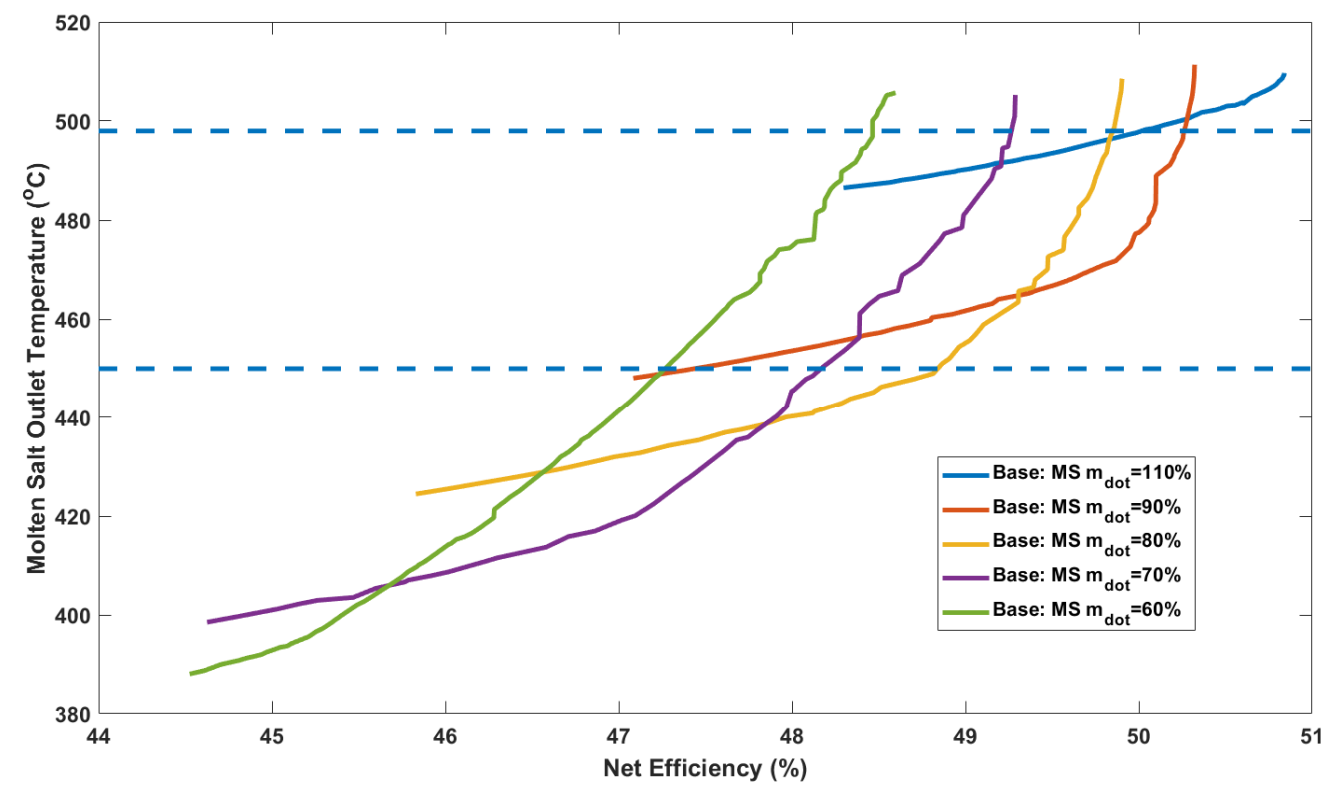

Fig. 11 MSOT across the Pareto front (shown in Fig. 10) for different MSFR (The dashed blue lines represent the $102 \%$ design MSOT and freezing limit of molten salt)

Fig. 11 shows the MSOT across the Pareto front and it is clear that the reduction in the molten salt mass flow rate also reduces the upper value of MSOT, therefore, the deviation of the MSFR does not negatively affect the solar field/TES capacity. Nevertheless, it is worth noting that the minimum MSOT reduces with the reduction in MSFR, which can be a concern depending on the freezing point of the selected molten salt. Since the melting temperature of the selected molten salt in this study is $424{ }^{\circ} \mathrm{C}$, a minimum MSOT temperature limit of $430{ }^{\circ} \mathrm{C}$ is considered in this work, nonetheless, this was not enforced as a minimum constraint in the optimisation in order to explore the complete Pareto front. It has to be noted however that the maximum power can not be realised when the MSFR is lower than $70 \%$ of the design value if the minimum MSOT constraint limits the operation (Fig. 11). Hence, selecting a molten salt with lower freezing temperature could eliminate this problem. According to Fig. 12 (a), the compressor inlet pressure is not strictly smooth, however, it is increasing from the maximum net power case to the maximum efficiency case until $70 \%$ molten salt mass flow. 


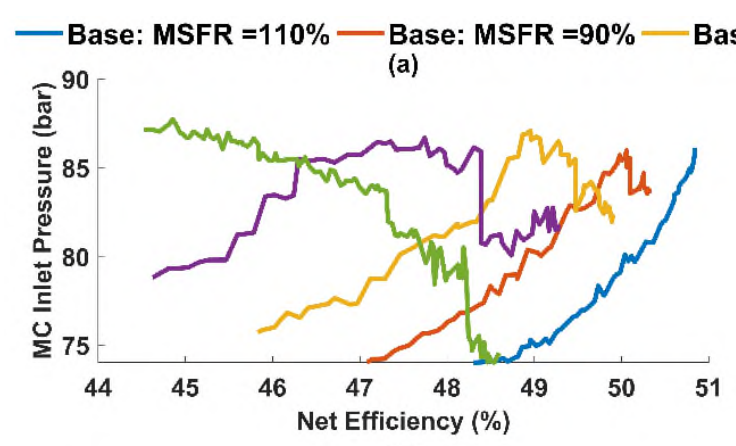

(c)

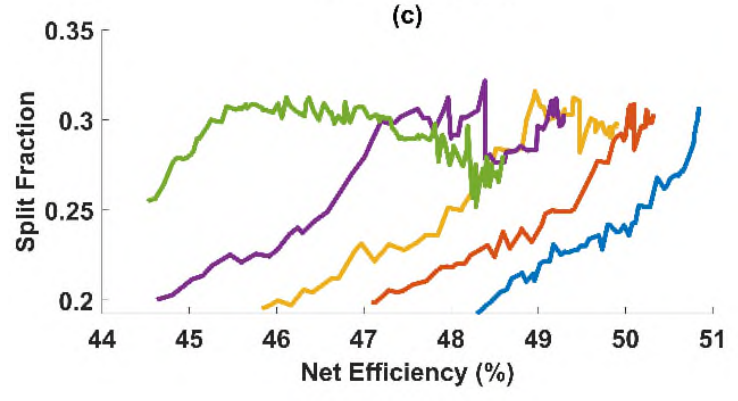

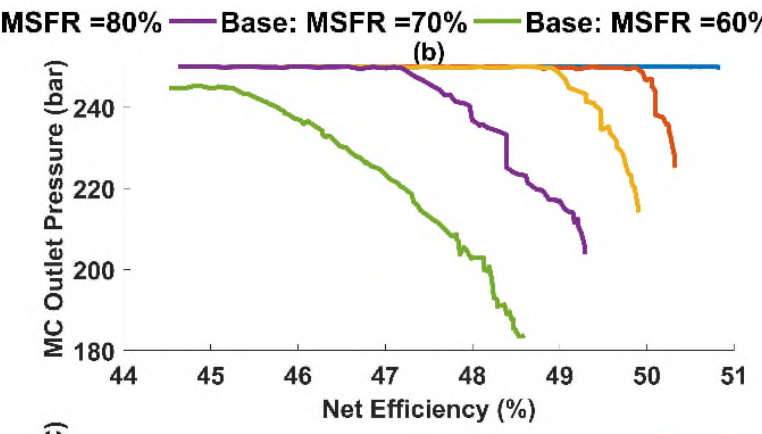

(d)

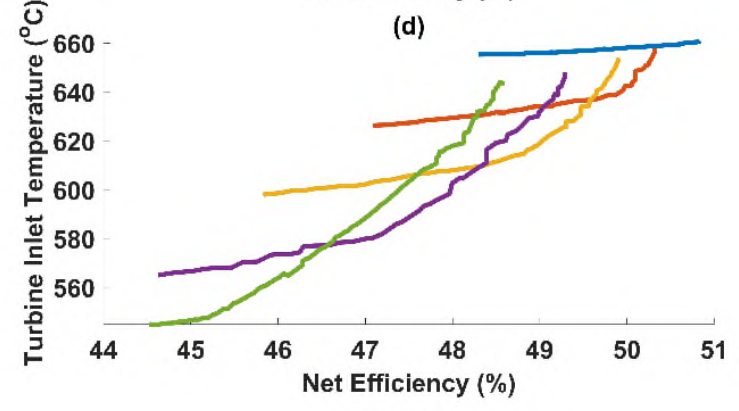

Fig. 12 Process variables trends across the Pareto front (shown in Fig. 10) for different MSFR: a) Main compressor Inlet Pressure, b) Main compressor Outlet Pressure, c) Split Fraction, d) Turbine Inlet Temperature

At $60 \%$ mass flow, a higher value of minimum pressure occurs at the maximum power case. The compressor outlet pressure reduces for the maximum efficiency case whilst it is higher for the maximum net power case (Fig. 12 (b)). The difference between the compressor outlet pressure for the maximum net power Case and the maximum efficiency case increases as the MSFR reduces. Only at 60\% MSFR, the cycle maximum pressure is lower than the upper bound value. The split fraction reaches its lower value for the maximum net power case and it reaches a maximum value for the maximum efficiency case (Fig. 12 (c)). The maximum and minimum split ratio values are not significantly changed up to $70 \%$ of the MSFR and the range reduces at $60 \%$ molten salt mass flow. This indicates that the split fraction control is not significant for a reduction in MSFR upto $~ 70 \%$. TIT reaches a maximum value at the maximum efficiency cases and the absolute magnitude reduces as the molten salt mass flow rate reduces, which implies that the TIT need to be controlled when the MSFR is reduced in order to maximise the cycle efficiency. It is worth noting from Fig. 12 (d) that the TIT doesn't reach the maximum value $\left(\sim 650^{\circ} \mathrm{C}\right)$ at a lower mass flow rate and this infers that the gain in the Carnot efficiency is not significant as compared to the efficiency loss from the turbomachinery. Furthermore, the cycle pressure ratio at the maximum efficiency case shows a declining trend because of the reduced compressor outlet pressure, whilst it is constant for monoatomic gas cycles. This infers that the changes in the cycle pressure impact the specific heat capacity and speed of sound significantly, which changes the cycle optimal pressure ratio. At $60 \%$ molten salt mass flow, the MSOT at the maximum net power case approaches close to the $\mathrm{sCO}_{2}$ inlet temperature to the PHEX. Further 
reduction of MSFR is expected to cause conflict as the recuperation has to be sacrificed in order to reach the minimum MSOT, which can limit the minimum MSOT. However, a CSP power plant is very unlikely to encounter such off-design scenarios, therefore, it is assumed to be less severe.
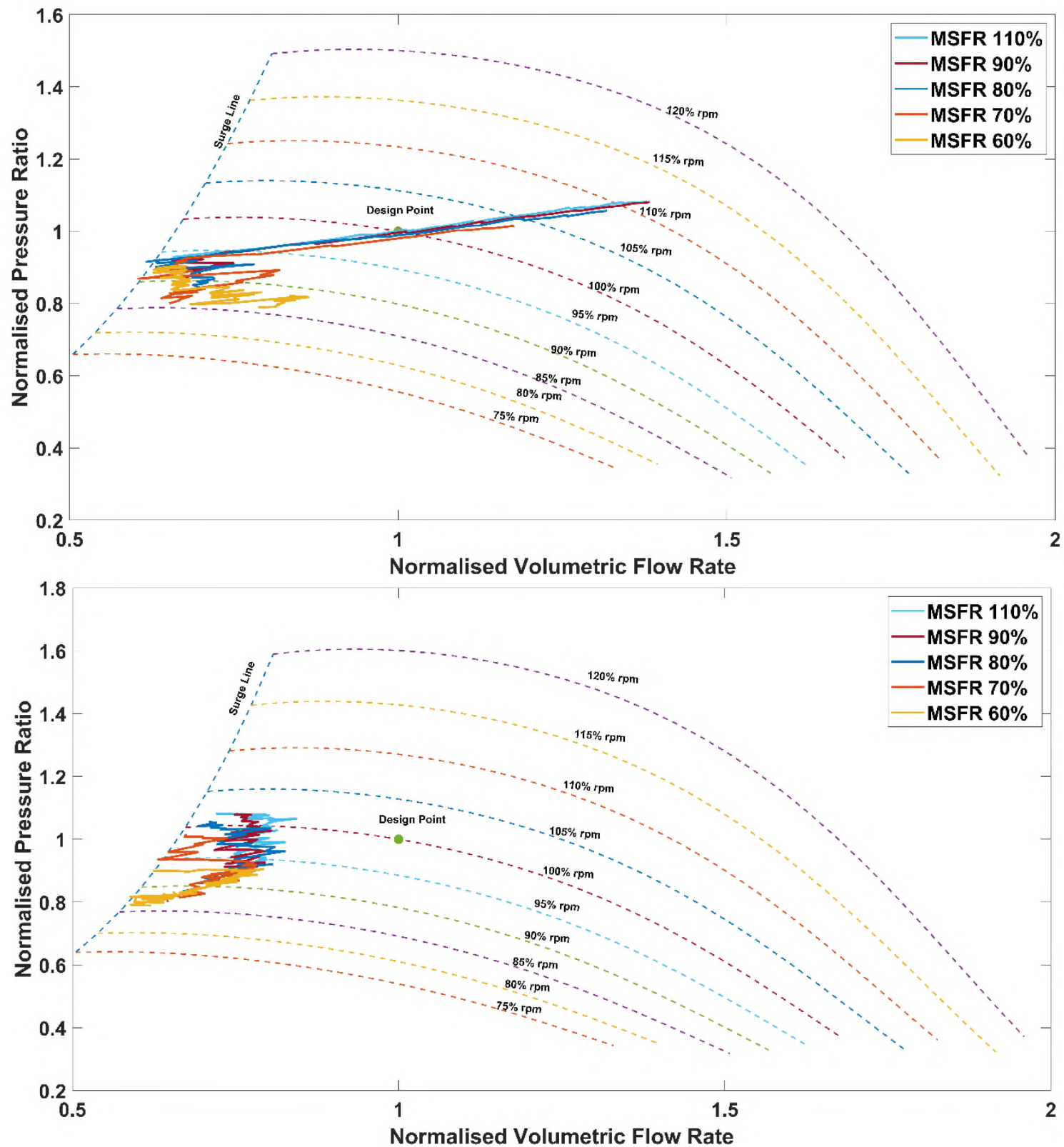

Fig. 13 Compressor operating point across the Pareto front (shown in Fig. 10) for different MSFR; a) Main

Compressor b) Recompressor

Fig. 13 shows the main compressor and recompressor operating points across the Pareto front overlay on the corresponding compressor maps. The main compressor operating points are similar for different MSFR when maximising net power whilst they slightly different one other when maximising efficiency (Fig. 13 (Top)). After 
a certain point, the main compressor pressure ratio reduces steeply with small changes in the volumetric flow to increase efficiency. This fall in pressure ratio can also be seen in Fig. 12 (b) where the compressor outlet pressure drops. On the other hand, the recompressor operates with the lesser change in their volumetric flow rate whilst the pressure ratio changes to match with the main compressor outlet pressure (Fig. 13 (Bottom)). The recompressor operates away from the design point owing to similar reasons discussed in section 6.1.

\subsection{Effect of Molten Salt Inlet Temperature Variation}

For changes to TIT in a given ideal gas closed-loop recuperated Brayton cycle, for a fixed CIT the PR has to reduce but without impacting the turbomachinery efficiencies significantly [56]. Since the $\mathrm{sCO}_{2}$ behaves like an ideal gas at a higher temperature, the cycle behaviour is expected to be similar to ideal gas closed cycle. This implies that the turbine inlet pressure has to be lowered in order to compensate for the increase in density at a lower TIT so that the turbine inlet volumetric flow rate remains close to the design value.

Fig. 14 shows four Pareto fronts for different MSITs and a CIT of $40^{\circ} \mathrm{C}$. The net power output can reach about $9 \%$ point higher power than the design value when the MSIT is $670{ }^{\circ} \mathrm{C}$, nevertheless, this might not be realisable if the turbine is not oversized. When MSIT is $610^{\circ} \mathrm{C}$, the net power fraction at the maximum power case is close to 1 and the efficiency is $45.04 \%$. The efficiency can be increased to $48.1 \%$ with a reduction of the net power fraction to around $90.4 \%$, however, this power is achieved by reducing the MSOT to $\sim 428{ }^{\circ} \mathrm{C}$, as shown in Fig. 15 (b), which is below the MSOT minimum freezing limit of $430{ }^{\circ} \mathrm{C}$. From Fig. 15 (a), the minimum pressure trend is roughly similar with a horizontal offset for all the MSITs studied, regardless of whether efficiency or net power is maximised, which infers that the main compressor inlet pressure is not influenced by changes in MSIT. On the other hand the compressor outlet pressure starts to drop with the MSIT, similar to ideal gas cycles. The cycle maximum pressure is 245.4 bar at a MSIT of $610{ }^{\circ} \mathrm{C}$ whilst maximising efficiency. Maximising the net power tends to maximise the cycle pressure ratio by reaching the minimum bound on the compressor inlet pressure (Fig. 15 (a)). The splitter ratio also shows a similar trend for all the MSIT studied with an offset (Fig. 15 (c)), indicating that no control of split fraction is required. The TIT for the maximum efficiency cases reached a maximum value (Fig. 15 (d)), showing that the power block operation is extended by lowering the MSOT when MSIT reduces and the efficiency drop is dominated by the reduction of the Carnot efficiency. Since the MSOT upper limit is not reached when the MSIT increases, MSOT constrained simulations were not performed, however, it has to be noted that the MSOT minimum limit was reached. 


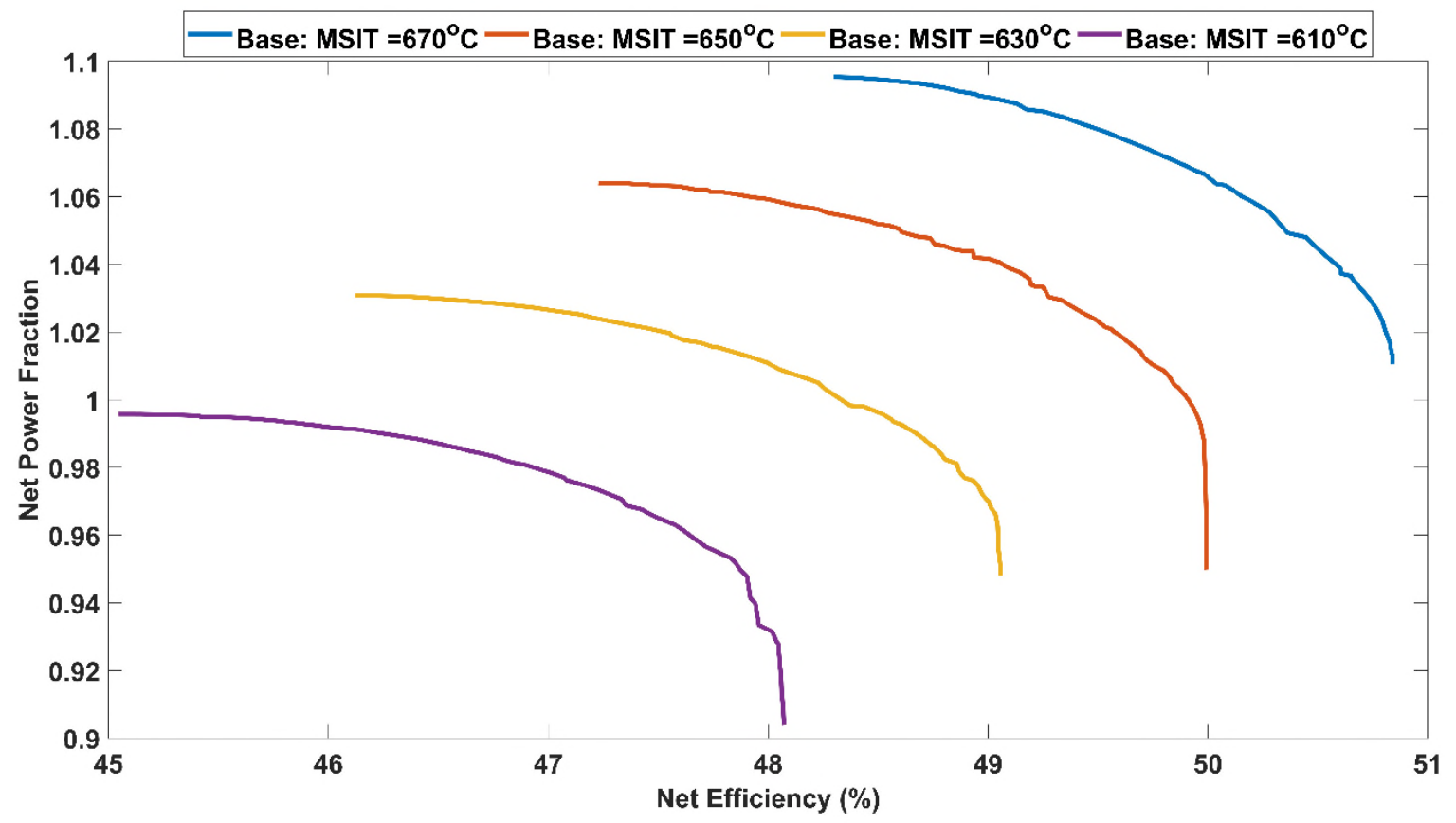

Fig. 14 Pareto fronts of recompression cycle for different MSIT
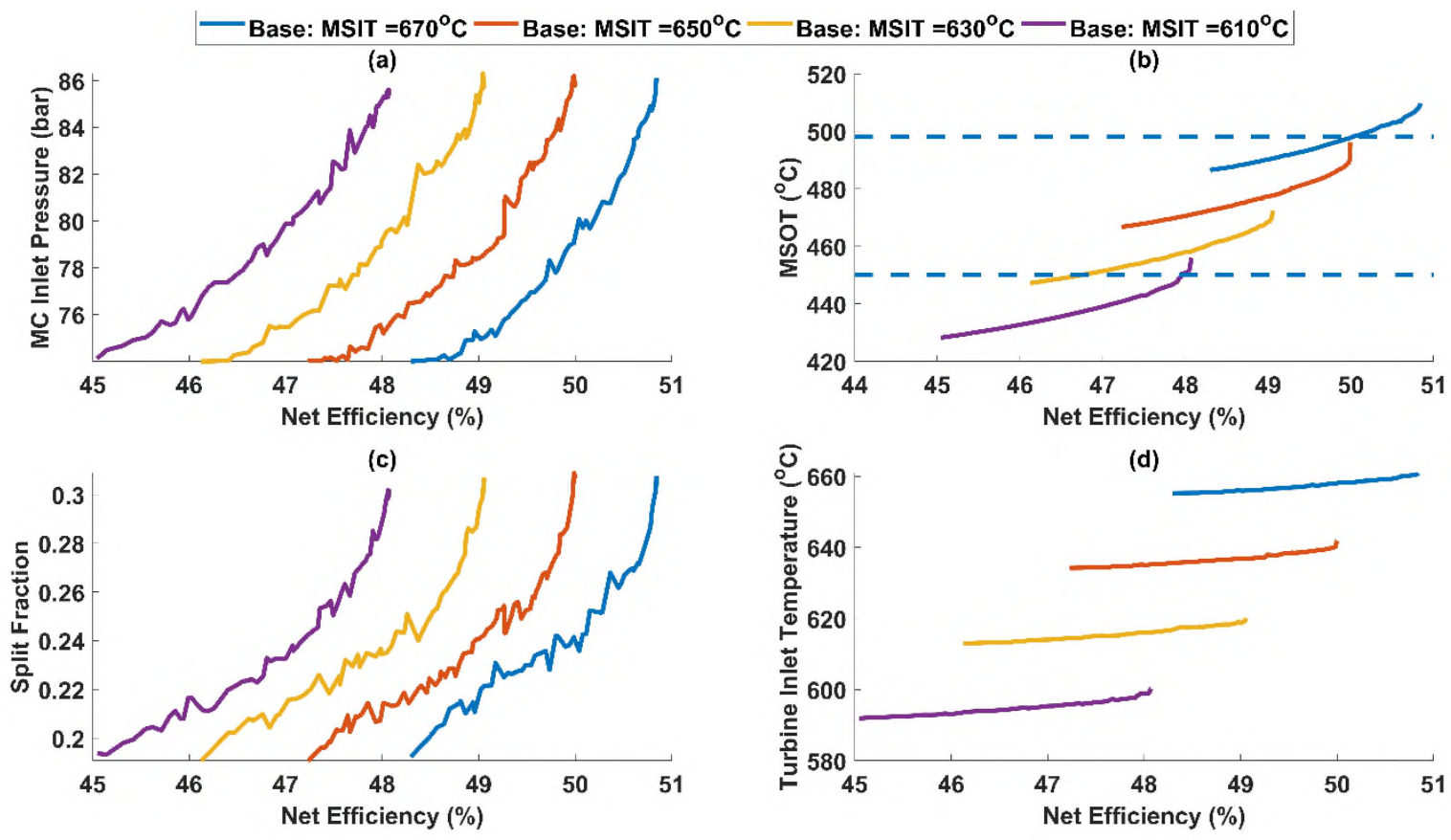

Fig. 15 Process variables trends across the Pareto front (shown in Fig. 14) for different MSIT: a) Main Compressor Inlet Pressure, b) Molten Salt Outlet Temperature, c) Split Fraction, d) Turbine Inlet Temperature 

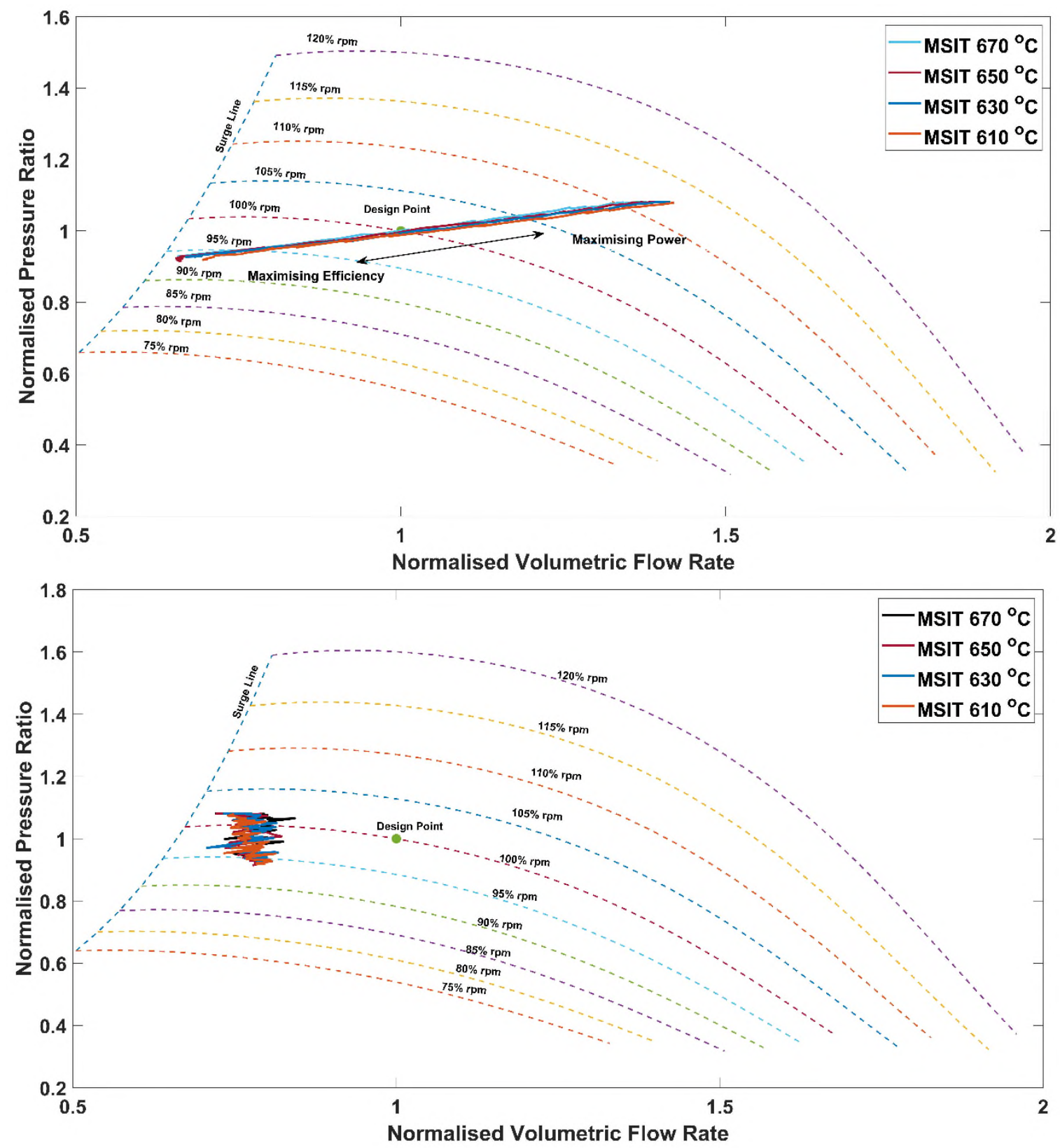

Fig. 16 Compressor operating point across the Pareto front (shown in Fig. 14) for different MSIT; Top) Main Compressor Bottom) Recompressor

The main compressor and recompressor operating points are plotted on top of the corresponding compressor maps as shown in Fig. 16, which indicates that changes in the MSIT do not influence either the main compressor or recompressor. However, the main compressor operates at a lower pressure ratio with a lower volumetric flow when maximising cycle efficiency compared to the maximum power case. On the other hand, the recompressor pressure ratio increases when maximising net power without a noticeable change in the volumetric flow, owing to the changes in the split fraction. 


\section{Annual Performance}

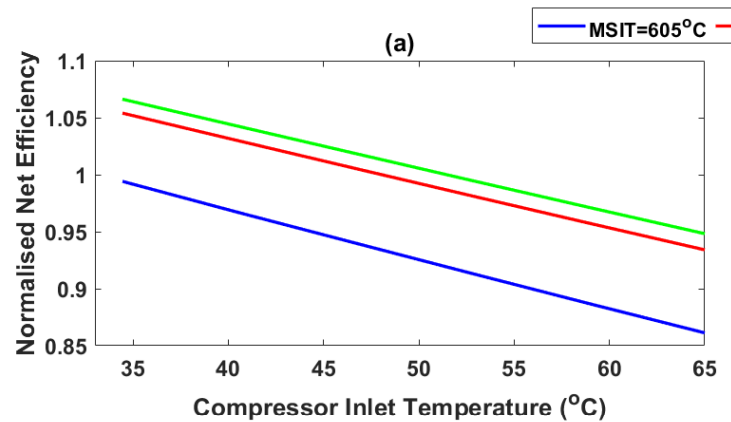

(b)

(c)
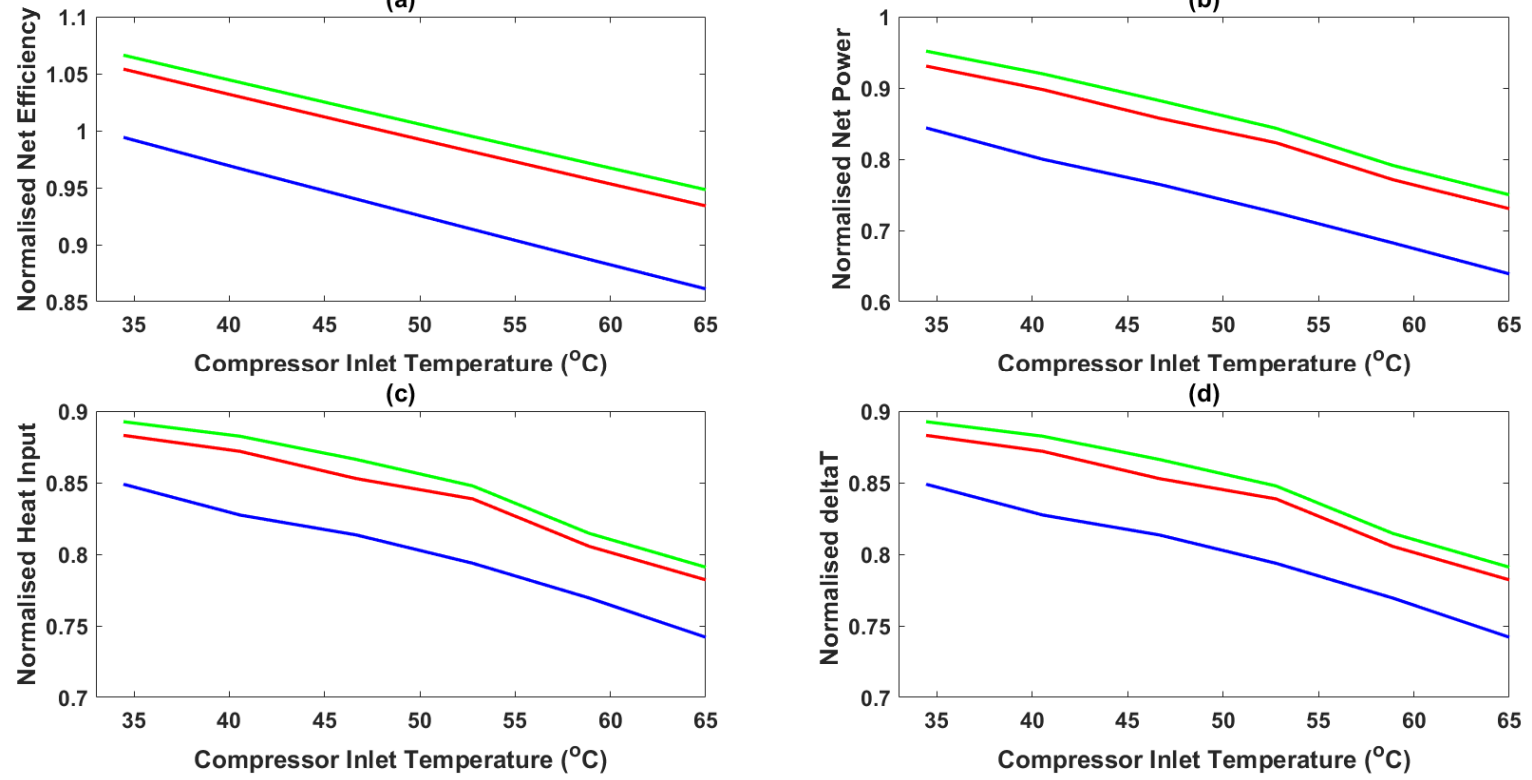

(d)

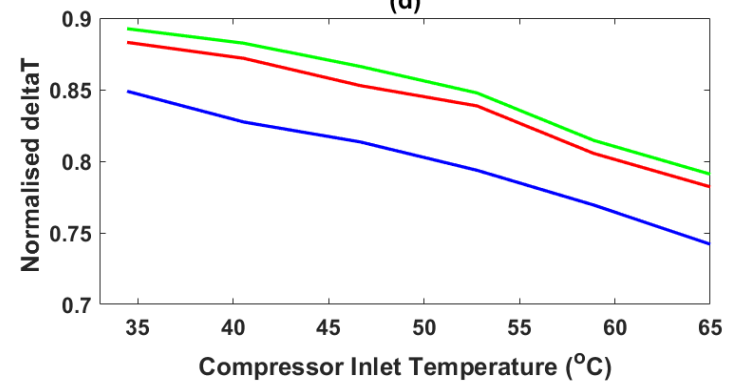

Fig. 17 Normalised performance when maximising efficiency for different Molten Salt Inlet Temperature (MSIT):

a) normalised net efficiency b) normalised net power c) normalised heat input d) normalised differential temperature across the primary heat exchanger
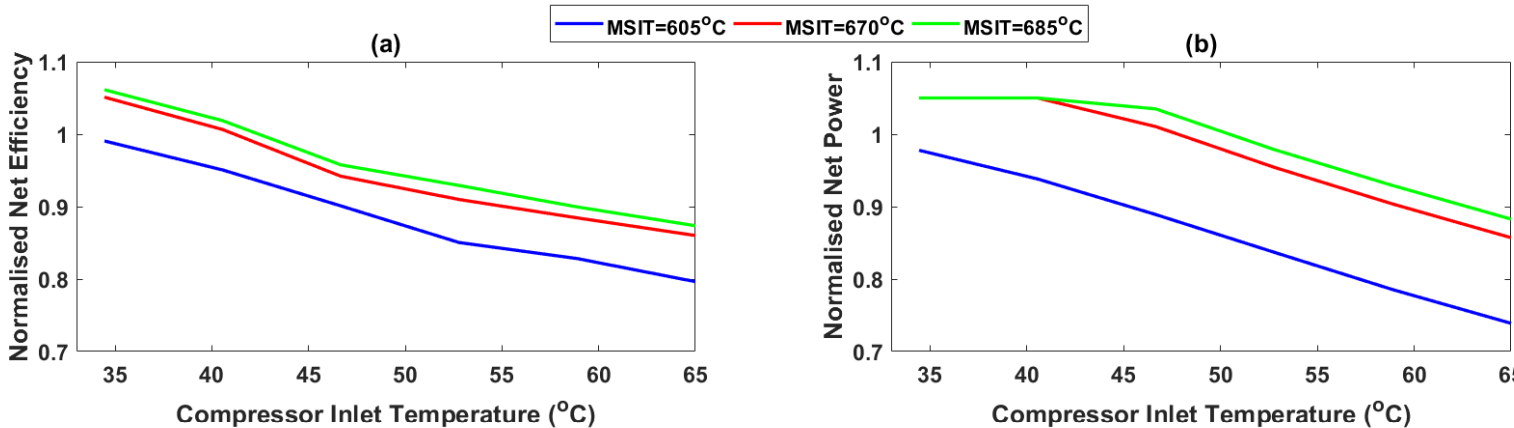

(c)

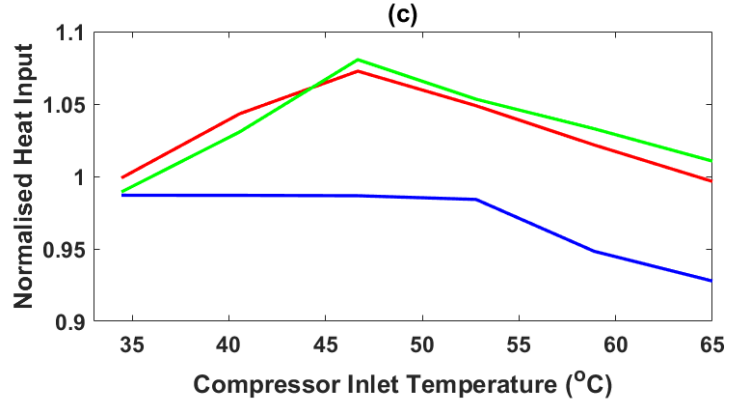

(d)

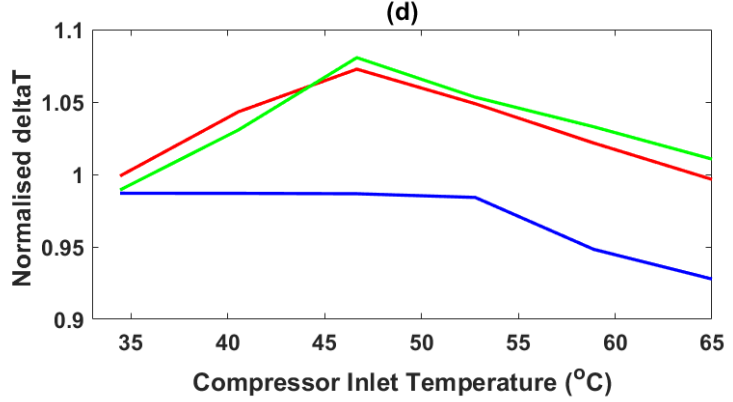

Fig. 18 Normalised performance when maximising net power for different Molten Salt Inlet Temperature (MSIT): a) normalised efficiency b) normalised net power $c$ ) normalised heat input d) normalised differential temperature across the primary heat exchanger 
In order to perform annual simulation, SAM requires the power cycle as a user-defined power cycle. A parametric table was therefore generated from SAM and each data point in the table set-up as a single-objective optimisation problem using a GA that maximises net efficiency while the MSOT freezing limit was imposed as a constraint. Since SAM maximises the net power of the recompression cycle, the maximum net power case was directly modelled in SAM. It is worth highlighting, however, that the compressor and turbine shaft speed are fixed to their design values in SAM whilst they were optimised in this study hence the results obtained from SAM would be a sub-optimal solution and it is therefore it is a conservative estimate for maximum power case.

The single objective optimisation results for different CITs are shown in Fig. 17 and Fig. 18 with Fig. 17 showing the normalised efficiency (referenced to the design condition), net power, heat input and differential temperature across the PHEX when maximising the net efficiency whilst Fig. 18 shows these parameters when maximising the net power. A linear increase in the efficiency above the design value is observed when the CIT is lower than $42{ }^{\circ} \mathrm{C}$, which is similar to the observations of Schmitt et al., and Bennett et al. [42,53]. The maximum power optimisation reached $105 \%$ of the design value, which is set as the maximum bound for the power. Consequently, the heat input and the $\Delta \mathrm{T}$ across the heat exchanger reaches its maximum around the design CIT. Similar cases were simulated for changes in the molten salt mass flow rate and MSIT and two sets of look-up tables were generated for the maximum efficiency and net power cases for implementation in SAM to perform the annual simulation.

Table 7 Annual performance of recompression cycle

\begin{tabular}{|l|c|c|c|}
\hline \multicolumn{1}{|c|}{ Description } & Unit & Maximum net power & Maximum efficiency \\
\hline Field Incident Annual Energy & MWh & 923,902 & 921,521 \\
\hline Receiver Incident Annual Energy & MWh & 454,183 & 371,589 \\
\hline Annual Energy absorbed by the HTF & MWh & 399,118 & 316,241 \\
\hline Annual Energy charged into TES & MWh & 225,473 & 202,742 \\
\hline Annual Energy discharged from TES & MWh & 215,609 & 192,531 \\
\hline Power Cycle Annual Gross Energy & MWh & 190,294 & 160,098 \\
\hline Annual Energy to Grid & MWh & 163,867 & 135,744 \\
\hline Capacity Factor & $\%$ & 63.0 & 52.2 \\
\hline Solar to Electric Conversion Efficiency & $\%$ & 17.7 & 14.7 \\
\hline LCOE & $\phi / k W h$ & 6.2 & 7.4 \\
\hline Number of Start-up & - & 283 & 147 \\
\hline
\end{tabular}

Table 7 shows a comparison of annual performance for the maximum the net power and maximum net efficiency cases. The plant capacity factor when maximising the efficiency is $10.8 \%$ lower than when maximising net power and consequently, the LCOE is $1.2 \phi / \mathrm{kWh}$ higher when the power cycle is operated for maximum efficiency. The 
annual solar to electric efficiency also drops from $17.7 \%$ to $14.7 \%$ when operating the power cycle in maximising efficiency mode since the solar field efficiency is roughly $9 \%$ point lower when maximising the power cycle efficiency. On the other hand, the number of start-ups is roughly $50 \%$ lower in comparison to maximising net power, however, the LCOE calculation in SAM assumes a fixed operational cost and therefore the significance of the number of start-ups is not fully captured here. Moreover, many commercial CSP plants are already operating at part load on moderate DNI days in order to avoid plant shutdown. Nonetheless, a detailed cost model is required to realise the benefits and the trade-off with sophisticated controls, which outside the scope of this study. The optimal operational strategy might be a combination of maximising net power and net efficiency depending on the DNI profile and sun angle.

\section{Conclusions}

The off-design performance of the recompression Brayton cycle was investigated for changes in the power cycle boundary conditions including ambient temperature, molten salt mass flow rate and molten salt inlet temperature. Multi-objective optimisations were performed to maximise the net power and efficiency for different off-design boundary conditions and the operational Pareto fronts with primary process variables were studied. The compressor inlet pressure for maximising the efficiency was estimated based on the assumption that the volumetric flow rate is the same as the design value at higher ambient temperatures with reasonable accuracy. At higher ambient temperatures, the molten salt outlet temperature from the power cycle is not affected when maximising the net power. When maximising the power cycle efficiency, however, molten salt outlet temperature increased by $46{ }^{\circ} \mathrm{C}$ implying that the TES capacity reduces by $25.1 \%$ as the temperature difference between hot and cold tanks reduces. On the other hand, constraining the power block operation to maintain the molten salt outlet temperature close to the design value penalises the efficiency by $0.8 \%$ point when the compressor inlet temperature is $55^{\circ} \mathrm{C}$ (design compressor inlet temperature $\left.=42{ }^{\circ} \mathrm{C}\right)$.

The main compressor over-speed limit can be a concern when maximising the net power at higher ambient temperatures whilst the main compressor surge margin can restrict the maximum net efficiency of the cycle at lower ambient temperatures. The recompressor design volumetric flow (i.e. split fraction and inlet pressure) selection influences the recompressor operation significantly, therefore, the primary mode of operation (i.e. maximising the power or efficiency) should be considered when sizing the recompressor. The split fraction does not require any control for changes in the molten salt inlet temperature and up to $\sim 70 \%$ reduction in molten salt flow rate, regardless of the mode of operation. On the other hand, the split fraction has to be reduced for an 
increase in compressor inlet temperature when maximising the efficiency.

The power cycle can be successfully operated in either maximum efficiency mode or maximum power mode showing a high degree of plant operational flexibility but an annual simulation identifies performance differences in these strategies. It was observed that the power cycle capacity factor increased by $\sim 10.8 \%$ with a subsequent reduction in the LCOE by $1.2 \notin / \mathrm{kWh}$ when operating in maximum power mode. On the other hand, the number of plant start-ups is reduced significantly (by approximately 50\%) when operating in maximum efficiency mode, which helps to increase plant life and reduce operational costs. The optimal operational strategy therefore could be a combination of maximising efficiency and net power according to prevailing ambient conditions.

\section{Acknowledgement}

This work was supported by the Biomass and Fossil Fuel Research Alliance (BF2RA) under grant 26-sCO $\mathrm{s}_{2}$ for efficient power generation and the Engineering and Physical Sciences Research Council, United Kingdom (EPSRC Grant No: EP/N029429/1). The authors would like to thank the Sir Richard Stapley Educational Trust for providing financial support for the year 2018-19. This work was co-funded by the Erasmus+ programme of the European Union and under the Programme "Department of Excellence" Legge 232/2016 (Grant No.CUP D94I18000260001).

\section{Data access}

Data underlying this paper can be accessed at https://doi.org/10.17862/cranfield.rd.13232378.

\section{References}

[1] Dostal V, Driscoll MJ, Hejzlar P. A Supercritical Carbon Dioxide Cycle for Next Generation Nuclear Reactors. 2004. doi:MIT-ANP-TR-100.

[2] Turchi CS, Ma Z, Neises T, Michael W. Thermodynamic Study of Advanced Supercritical Carbon Dioxide Power Cycles for High Performance Concentrating Solar Power Systems. Proc. ASME 2012 6th Int. Conf. Energy Sustain., 2012. doi:10.1115/ES2012-91179.

[3] Thanganadar D, Asfand F, Patchigolla K. Thermal performance and economic analysis of supercritical Carbon Dioxide cycles in combined cycle power plant. Appl Energy 2019;255:113836. doi:10.1016/j.apenergy.2019.113836.

[4] Crespi F, Gavagnin G, Sánchez D, Martínez GS. Supercritical carbon dioxide cycles for power generation: A review. Appl Energy 2017;195:152-83. doi:10.1016/j.apenergy.2017.02.048.

[5] Marchionni M, Bianchi G, Tassou SA. Techno-economic assessment of Joule-Brayton cycle architectures for heat to power conversion from high-grade heat sources using $\mathrm{CO}_{2}$ in the supercritical state. Energy 2018;148:1140-52. doi:10.1016/j.energy.2018.02.005. 
[6] Giovannelli A, Archilei EM, Di Lorenzo G, Salvini C, Bashir MA, Messina G. Design of power-blocks for medium-scale supercritical carbon dioxide plants. Int J Energy Res 2020:1-24. doi:10.1002/er.5539.

[7] Steven WA, Tom C, Edward P, Tom L, Gary R, J S-AA. Summary of the Sandia Supercritical CO Development Program. Int. SCO2 Power Cycle Symp., Boulder, Colorado: 2011.

[8] Lecompte S, Ntavou E, Tchanche B, Kosmadakis G, Pillai A, Manolakos D, et al. Review of experimental research on supercritical and transcritical thermodynamic cycles designed for heat recovery application. Appl Sci 2019;9:1-26. doi:10.3390/app9122571.

[9] Black \& Veatch. Molten Salt Concept Definition \& Capital Cost Estimate, Prepared for SunShot U.S. Department of Energy. 2016. doi:10.2172/1335150.

[10] Persichilli M, Kacludis A, Zdankiewicz E, Held T. Supercritical $\mathrm{CO}_{2}$ Power Cycle Developments and Commercialization: Why $\mathrm{sCO}_{2}$ can Displace Steam Steam. Power-Gen India Cent. Asia, 2012, p. 1-15.

[11] Wang X, Dai Y. Exergoeconomic analysis of utilizing the transcritical $\mathrm{CO}_{2}$ cycle and the ORC for a recompression supercritical $\mathrm{CO}_{2}$ cycle waste heat recovery: A comparative study. Appl Energy 2016;170:193-207. doi:10.1016/j.apenergy.2016.02.112.

[12] Asfand F, Thanganadar D, Patchigolla K. Thermodynamic performance of a supercritical $\mathrm{CO}_{2}$ cycle integrated with a recuperative absorption cooling system. ECOS 2019 - Proc. 32nd Int. Conf. Effic. Cost, Optim. Simul. Environ. Impact Energy Syst., vol. 2019- June, WROCLAW, POLAND: 2019, p. 3895-903.

[13] Linares JI, Montes MJ, Cantizano A, Sánchez C. A novel supercritical $\mathrm{CO}_{2}$ recompression Brayton power cycle for power tower concentrating solar plants. Appl Energy 2020;263:114644. doi:10.1016/j.apenergy.2020.114644.

[14] Clementoni EM, Cox TL, King MA. Steady-State Power Operation Of A Supercritical Carbon Dioxide Brayton Cycle With Thermal-Hydraulic Control. ASME Turbo Expo 2016 Turbomach. Tech. Conf. Expo., Seoul, South Korea: 2016, p. 1-10. doi:10.1115/GT2016-56038.

[15] Clementoni EM, Cox TL, King MA. Off-Nominal Component Performance in a Supercritical Carbon Dioxide Brayton Cycle. J Eng Gas Turbines Power 2015;138:011703. doi:10.1115/1.4031182.

[16] Clementoni EM, Cox TL, King MA, Rahner KD. Transient power operation of a supercritical carbon dioxide Brayton cycle. ASME Turbo Expo, Charlotte, NC, USA: 2017. doi:10.1115/GT2017-63056.

[17] Clementoni EM, Cox TL. Effect of compressor inlet pressure on cycle performance for a supercritical carbon dioxide brayton cycle. 6th Int. Supercrit. CO2 Power Cycles Symp., vol. 9, Pittsburgh, Pennsylvania: 2018, p. 2-10.

[18] Clementoni EM, Cox TL. Effect of compressor inlet pressure on cycle performance for a supercritical carbon dioxide brayton cycle. Proc. ASME Turbo Expo, vol. 9, Oslo, Norway: 2018, p. 1-8. doi:10.1115/GT2018-75182.

[19] Anselmi E, Johnston M, Bunce I. An Overview of the Rolls-Royce $\mathrm{sCO}_{2}$ Test Rig Project at Cranfield. 6th Int. Symp. - Supercrit. CO2 Power Cycles, Pittsburgh, Pennsylvania: 2018.

[20] Duniam S, Veeraragavan A. Off-design performance of the supercritical carbon dioxide recompression Brayton cycle with NDDCT cooling for concentrating solar power. Energy 2019;187:115992. doi:10.1016/j.energy.2019.115992.

[21] Wright SA, Davidson CS, Husa C. Off-design performance modeling results for a supercritical $\mathrm{CO}_{2}$ waste heat recovery power system. 6th Int Symp - Supercrit CO2 Power Cycles 2018:1-10.

[22] Wang X, Li X, Li Q, Liu L, Liu C. Performance of a solar thermal power plant with direct air-cooled 
supercritical carbon dioxide Brayton cycle under off-design conditions. Appl Energy 2020;261:114359. doi:10.1016/j.apenergy.2019.114359.

[23] Son S, Jeong Y, Cho SK, Lee JI. Development of supercritical $\mathrm{CO}_{2}$ turbomachinery off-design model using 1D mean-line method and Deep Neural Network. Appl Energy 2020;263:114645. doi:10.1016/j.apenergy.2020.114645.

[24] Yan XL. Dynamic Analysis and Control System Design for an Advanced Nuclear Gas Turbine Power Plant. Massachusetts Institute of Technology, 1990.

[25] J.H.Horlock. Advanced Gas Turbine Cycles. 1st ed. Pergamon; 2003.

[26] Frutschi HU. Closed-Cycle Gas Turbines: Operating Experience and Future Potential. ASME Press; 2005. doi:10.1115/1.802264.

[27] Lemmon EW, Huber ML, McLinden MO. NIST Standard Reference Database 23. Natl Inst Stand Technol 2013;V 9.1.

[28] Xu X, Wang X, Li P, Li Y, Hao Q, Xiao B, et al. Experimental Test of Properties of KCl- $\mathrm{MgCl}_{2}$ Eutectic Molten Salt for Heat Transfer and Thermal Storage Fluid in Concentrated Solar Power Systems. J Sol Energy Eng 2018;140:051011. doi:10.1115/1.4040065.

[29] Jerden J. Molten Salt Thermophysical Properties Database Development : 2019 Update. 2019. doi:10.2172/1559846.

[30] Nellis G, Klein S. Heat Transfer. 2009. doi:10.1017/CBO9780511841606.

[31] BALJE O. Turbomachines: A Guide to Design, Selection and Therapy. John Wiley \& Sons; 1981. doi: $10.1115 / 1.3241788$.

[32] Dyreby JJ, Klein SA, Nellis GF, Reindl DT. Modeling off-design and part-load performance of supercritical carbon dioxide power cycles. Proc. ASME Turbo Expo, vol. 8, San Antonio, Texas, USA: 2013, p. 1-7. doi:10.1115/GT2013-95824.

[33] Liese E, Zitney SE. The Impeller Exit Flow Coefficient As a Performance Map Variable for Predicting Centrifugal Compressor Off-Design Operation Applied to a Supercritical $\mathrm{CO}_{2}$ Working Fluid. Proc. ASME Turbo Expo 2017 Turbomach. Tech. Conf. Expo. Supercrit. CO2 Power Cycles; Wind Energy, 2017, p. V009T38A003. doi:10.1115/GT2017-63090.

[34] Fleming DD, Conboy TM, Pasch JJ, Rochau GA, Fuller RL, Holschuh T V, et al. Scaling Considerations for a Multi- Megawatt Class Supercritical $\mathrm{CO}_{2}$ Brayton Cycle and Commercialization. vol. SAND2013-9. 2013.

[35] Dyreby JJ. Modeling the Supercritical Carbon Dioxide Brayton Cycle with Recompression 2010:155. doi:10.1088/1751-8113/44/8/085201.

[36] Patnode A. Simulation and performance evaluation of parabolic trough solar power plants. Univ Wisconsin-Madison 2006;Master:5-271.

[37] Tang C-J, Hofer D, Mcclung A, Megan Huang. Transient modeling of $10 \mathrm{MW}$ supercritical $\mathrm{CO}_{2}$ Brayton power cycles using Numerical Propulsion System Simulation (NPSS). ASME Turbo Expo 2019, 2019, p. 1-10.

[38] Clementoni EM, Cox TL, King MA. Response of a compact recuperator to thermal transients in a supercritical carbon dioxide Brayton cycle. ASME Turbo Expo 2017:1-11. doi:10.1115/GT2017-63058.

[39] Jiang Y, Liese E, Zitney SE, Bhattacharyya D. Design and dynamic modeling of printed circuit heat exchangers for supercritical carbon dioxide Brayton power cycles. Appl Energy 2018;231:1019-32. 
doi:10.1016/j.apenergy.2018.09.193.

[40] Halimi B, Suh KY. Computational analysis of supercritical $\mathrm{CO}_{2}$ Brayton cycle power conversion system for fusion reactor. Energy Convers Manag 2012;63:38-43. doi:10.1016/j.enconman.2012.01.028.

[41] Neises T, Turchi C. A comparison of supercritical carbon dioxide power cycle configurations with an emphasis on CSP applications. Energy Procedia 2013;49:1187-96. doi:10.1016/j.egypro.2014.03.128.

[42] Schmitt J, Wilkes J, Bennett J, Wygant K, Pelton R. Lowering the levelized cost of electricity of a concentrating solar power tower with a supercritical carbon dioxide power cycle. ASME Turbo Expo, Charlotte, NC, USA: 2017, p. 1-10. doi:10.1115/GT2017-64958.

[43] De la Calle A, Bayon A, Soo Too YC. Impact of ambient temperature on supercritical $\mathrm{CO}_{2}$ recompression Brayton cycle in arid locations: Finding the optimal design conditions. Energy 2018;153:1016-27. doi:10.1016/j.energy.2018.04.019.

[44] Deb K, Pratap A, Agarwal S, Meyarivan T. A fast and elitist multiobjective genetic algorithm: NSGAII. IEEE Trans Evol Comput 2002;6:182-97. doi:10.1109/4235.996017.

[45] Avval HB, Ahmadi P, Ghaffarizadeh AR, Saidi MH. Thermo-economic-environmental multiobjective optimization of a gas turbine power plant with preheater using evolutionary algorithm. Int J Energy Res 2010. doi:10.1002/er.1696.

[46] Rangaiah GP. Multi-Objective Optimization Techniques and Applications in Chemical Engineering. vol. 1. 2009. doi:10.1007/0-387-28356-0_10.

[47] Wong JYQ, Sharma S, Rangaiah GP. Design of shell-and-tube heat exchangers for multiple objectives using elitist non-dominated sorting genetic algorithm with termination criteria. Appl Therm Eng 2016;93:888-99. doi:10.1016/j.applthermaleng.2015.10.055.

[48] Sharma S, Rangaiah GP, Cheah KS. Multi-objective optimization using MS Excel with an application to design of a falling-film evaporator system. Food Bioprod Process 2011;90:123-34. doi:10.1016/j.fbp.2011.02.005.

[49] Kulhánek M, Dostál V. Thermodynamic Analysis and Comparison of Supercritical Carbon Dioxide Cycles. Proc SCCO2 Power Cycle Symp 2011:1-7.

[50] Turchi CS, Ma Z, Neises T, Michael W. Thermodynamic Study of Advanced Supercritical Carbon Dioxide Power Cycles for High Performance Concentrating Solar Power Systems. Proc. ASME 2012 6th Int. Conf. Energy Sustain., n.d., p. 375-83. doi:10.1115/ES2012-91179.

[51] Mehos M, Turchi C, Jorgenson J. Advancing Concentrating Solar Power Technology, Performance, and Dispatchability. Sandia Rep 2016;NREL/TP-55:1-66. doi:10.1016/B978-0-08-087872-0.00319-X.

[52] Carstens NA. Control strategies for supercritical carbon dioxide power conversion systems. Massachusetts Institute of Technology, 2007.

[53] Bennett J, Wilkes J, Allison T, Pelton R, Wygant K. Cycle modeling and optimization of an integrally geared $\mathrm{sCO}_{2}$ compander. ASME Turbo Expo, Charlotte, NC, USA: 2017, p. 1-8. doi:10.1115/GT201763707.

[54] Invernizzi CM. Closed power cycles: Thermodynamic fundamentals and applications. Lect Notes Energy 2013;11. doi:10.1007/978-1-4471-5140-1.

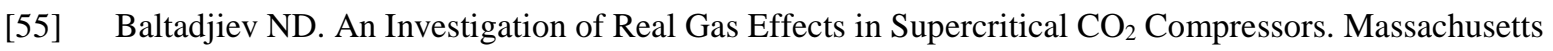
Institute of Technology, 2012. doi:10.1115/1.4029616.

[56] Gad-Briggs A, Pilidis P, Nikolaidis T. Analyses of the Control System Strategies and Methodology for 
Part Power Control of the Simple and Intercooled Recuperated Brayton Helium Gas Turbine Cycles for Generation IV Nuclear Power Plants. J Nucl Eng Radiat Sci 2017;3. doi:10.1115/1.4036737. 
2020-11-18

Off-design and annual performance analysis of supercritical carbon dioxide cycle with thermal storage for CSP application

Thanganadar, Dhinesh

Elsevier

Thanganadar D, Fornarelli F, Camporeale S, et al., (2021) Off-design and annual performance analysis of supercritical carbon dioxide cycle with thermal storage for CSP application. Applied Energy, Volume 282, Part A, Article number 116200

https://doi.org/10.1016/j.apenergy.2020.116200

Downloaded from Cranfield Library Services E-Repository 